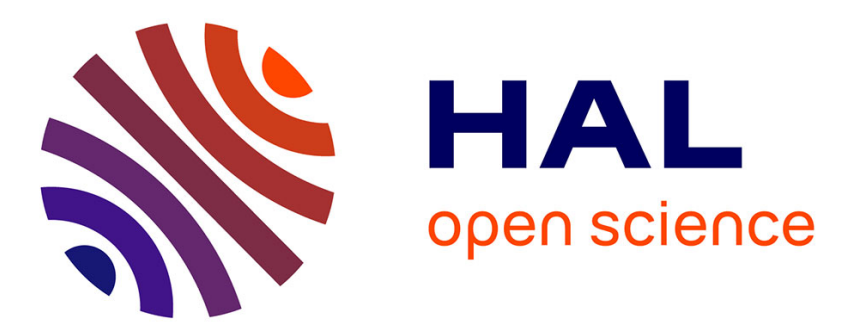

\title{
Densities and temperatures in the Venus mesosphere and lower thermosphere retrieved from SOIR on board Venus Express: Retrieval technique
}

A. Mahieux, A. C. Vandaele, E. Neefs, S. Robert, V. Wilquet, R. Drummond, Anna Fedorova, Jean-Loup Bertaux

\section{To cite this version:}

A. Mahieux, A. C. Vandaele, E. Neefs, S. Robert, V. Wilquet, et al.. Densities and temperatures in the Venus mesosphere and lower thermosphere retrieved from SOIR on board Venus Express: Retrieval technique. Journal of Geophysical Research. Planets, 2010, 115 (E12), pp.E12014. 10.1029/2010JE003589 . hal-00516608

\section{HAL Id: hal-00516608 \\ https://hal.science/hal-00516608}

Submitted on 22 Feb 2016

HAL is a multi-disciplinary open access archive for the deposit and dissemination of scientific research documents, whether they are published or not. The documents may come from teaching and research institutions in France or abroad, or from public or private research centers.
L'archive ouverte pluridisciplinaire HAL, est destinée au dépôt et à la diffusion de documents scientifiques de niveau recherche, publiés ou non, émanant des établissements d'enseignement et de recherche français ou étrangers, des laboratoires publics ou privés. 


\title{
Densities and temperatures in the Venus mesosphere and lower thermosphere retrieved from SOIR on board Venus Express: Retrieval technique
}

\author{
A. Mahieux, ${ }^{1}$ A. C. Vandaele, ${ }^{1}$ E. Neefs, ${ }^{1}$ S. Robert, ${ }^{1}$ V. Wilquet, ${ }^{1}$ R. Drummond, ${ }^{1}$ \\ A. Federova, ${ }^{2}$ and J. L. Bertaux ${ }^{3}$ \\ Received 24 February 2010; revised 20 August 2010; accepted 2 September 2010; published 23 December 2010.
}

[1] The SOIR instrument, flying on board Venus Express, operates in the infrared spectral domain and uses the solar occultation technique to determine the vertical profiles of several key constituents of the Venus atmosphere. The retrieval algorithm is based on the optimal estimation method, and solves the problem simultaneously on all spectra belonging to one occultation sequence. Vertical profiles of $\mathrm{H}_{2} \mathrm{O}, \mathrm{CO}, \mathrm{HCl}$, and $\mathrm{HF}$, as well as some of their isotopologues, are routinely obtained for altitudes ranging typically from 70 to $120 \mathrm{~km}$, depending on the species and the spectral region recorded. In the case of $\mathrm{CO}_{2}$, a vertical profile from 70 up to $150 \mathrm{~km}$ can be obtained by combining different spectral intervals. Rotational temperature is also retrieved directly from the $\mathrm{CO}_{2}$ signature in the spectra. The present paper describes the method used to derive the above mentioned atmospheric quantities and temperature profiles. The method is applied on some retrieval cases illustrating the capabilities of the technique. More examples of results will be presented and discussed in a following companion paper which will focus on the $\mathrm{CO}_{2}$ vertical profiles of the whole data set.

Citation: Mahieux, A., A. C. Vandaele, E. Neefs, S. Robert, V. Wilquet, R. Drummond, A. Federova, and J. L. Bertaux (2010), Densities and temperatures in the Venus mesosphere and lower thermosphere retrieved from SOIR on board Venus Express: Retrieval technique, J. Geophys. Res., 115, E12014, doi:10.1029/2010JE003589.

\section{Introduction}

[2] Venus is known to be a very warm planet with a dense atmosphere. Its mesosphere extending from the cloud deck up to $\sim 100 \mathrm{~km}$ is composed mainly of carbon dioxide $\left(\mathrm{CO}_{2}, 96.5 \%\right)$ and Nitrogen $\left(\mathrm{N}_{2}, 3.5 \%\right)$. This region is dynamically and photochemically very active, but has been up to now poorly observed. Previous measurements indeed focused essentially on the regions below the clouds down to the surface. The mesosphere acts as a transition region between the lower atmosphere, and its cloud deck and superrotational zonal winds, and the thermosphere, dominated by the subsolar to antisolar circulation. The altitude of $100 \mathrm{~km}$ is a natural boundary in the atmosphere of Venus. The information above $100 \mathrm{~km}$ altitude about temperature, pressure, the densities of carbon dioxide and other minor atmospheric constituents, their sources and sinks, as well as the reactions in which they are involved, is incomplete, as only scarce measurements have been performed [Clancy et al., 2003; Sandor and Clancy, 2005;

\footnotetext{
${ }^{1}$ Planetary Aeronomy, Belgian Institute for Space Aeronomy, Brussels,

${ }^{2}$ Space Research Institute, Moscow, Russia.

${ }^{3}$ LATMOS, Guyancourt, France.
} Belgium.

Copyright 2010 by the American Geophysical Union. 0148-0227/10/2010JE003589
Clancy et al., 2008]. Chemically active species, such as sulphur-bearing gases (COS, $\left.\mathrm{SO}_{2}\right)$ and halides ( $\left.\mathrm{HCl}, \mathrm{HF}\right)$ have already been reported [de Bergh et al., 2006] but below $70 \mathrm{~km}$ altitude.

[3] The Solar Occultation in the Infrared (SOIR) spectrometer is an extension of the French instrument SPICAV, the combination being called SPICAV/SOIR [Bertaux et al., 2007; Svedhem et al., 2007]. SPICAV/SOIR is one of the seven instruments on board Venus Express (VEX), a planetary mission of the European Space Agency (ESA) that was launched in November 2005 and inserted into a polar orbit around Venus in April 2006 [Titov et al., 2006]. VEX is orbiting around Venus on a polar orbit, which allows the instrument to sound almost all latitudes. The region comprised between $40^{\circ}$ and $60^{\circ}$ North is however more difficult to sound due to the orbit shape.

[4] SOIR is the first high-resolution near-infrared spectrometer on board a spacecraft investigating the Venusian mesosphere where it detected $\mathrm{H}_{2} \mathrm{O}$ and HDO [Fedorova et al., 2008], $\mathrm{SO}_{2}$ [Belyaev et al., 2008], $\mathrm{HCl}, \mathrm{HF}, \mathrm{CO}$, and $\mathrm{CO}_{2}$ [Vandaele et al., 2008; Belyaev et al., 2008; Fedorova et al., 2008; Vandaele et al., 2008] The newness of such a spectrometer and the high accuracy obtained allow us to measure Venus' atmosphere minor constituents as well as $\mathrm{CO}_{2}$ absorption lines with a never-so-far obtained resolution from orbit. The solar occultation technique is used for the first time at Venus. This technique has the advantage of being a 
Table 1. Summary of Pixel Rows Combinations

\begin{tabular}{cccc}
\hline Denomination & $\begin{array}{c}\text { Number of Scanned } \\
\text { Orders per Second }\end{array}$ & $\begin{array}{c}\text { Number of Lines } \\
\text { in Each Group }\end{array}$ & $\begin{array}{c}\text { Number of } \\
\text { Lines Groups }\end{array}$ \\
\hline $2 \times 16$ & 4 & 16 & 2 \\
$2 \times 12$ & 4 & 12 & 2 \\
$4 \times 4$ & 2 & 4 & 4 \\
$4 \times 3$ & 2 & 3 & 4 \\
$8 \times 4$ & 1 & 4 & 8 \\
$8 \times 3$ & 1 & 3 & 8 \\
\hline
\end{tabular}

self calibrated method, as will explained below in the text. The retrieval method developed in this study will be discussed in details in terms of sensitivity and error sources. The algorithm will be used to derive the atmospheric parameters from the spectra measured in two different regions during an occultation: $\mathrm{CO}_{2}, \mathrm{CO}$ and temperature vertical profiles will be derived. We will also show that information on the temperature can be retrieved directly from the spectra. Comprehensive results considering $\mathrm{CO}_{2}$ will be given in a companion paper (A. Mahieux et al., Densities and temperatures in the Venus mesosphere and lower thermosphere retrieved from SOIR on board Venus Express: $\mathrm{CO}_{2}$ densities and temperatures, manuscript in preparation, 2010) in which the focus will be made on temporal as well as latitudinal distribution of the $\mathrm{CO}_{2}$ density and temperature.

\section{SOIR Instrument}

[5] SOIR is an innovative, compact, high-resolution spectrometer for remote infrared measurements of gaseous species of the Venus' atmosphere, which has been already extensively described [Nevejans et al., 2006; Mahieux et al., 2008, 2009]. A short description of its working principles will be given here. The system consists of an echelle grating spectrometer working in the infrared (IR) combined with an acousto optic tunable filter (AOTF) for the selection of diffraction grating orders. Such an instrument combines the advantages of a high spectral resolution, fast and flexible access to any part of its spectral domain, compactness, no moving parts and low mass. The SOIR instrument is designed to measure at high resolution $\left(\sim 0.15 \mathrm{~cm}^{-1}\right)$ the atmospheric transmission in the IR, between 2.2 and $4.3 \mu \mathrm{m}$ $\left(2200-4400 \mathrm{~cm}^{-1}\right)$.

[6] The AOTF is driven by high radio frequencies (RF) that may be tuned for selecting the band-pass wave number range. The AOTF is a fast response solid state $\mathrm{TeO}_{2}$ optical filter, whose transfer function has been extensively investigated by Mahieux et al. [2009] and may be approximated by the sum of sinc squared functions, where $\operatorname{sinc}(\mathrm{x})$ is defined as $\sin (\pi \mathrm{x}) / \pi \mathrm{x}$, $\mathrm{x}$ being the independent variable, here the RF. The main lobe of the sinc square-like function has a full width at half maximum (FWHM) of about $24 \mathrm{~cm}^{-1}$. The shape of the AOTF transfer function varies significantly along the wave number range [Mahieux et al., 2009].

[7] The echelle grating of SOIR divides the spectral range into 94 useful diffraction orders, ranging from 101 to 194. The bandwidth varies from $19.3 \mathrm{~cm}^{-1}$ in diffraction order 101 to $37.1 \mathrm{~cm}^{-1}$ in order 194 . The free spectral range (FSR) of SOIR equals $22.38 \mathrm{~cm}^{-1}$. In diffraction orders 101 to 122 , the FSR is greater than the bandwidth, and hence, the detector will lose part of the spectrum. The opposite occurs in diffraction orders 123 to 194 , where only a part of the detector will be covered by the diffracted order. Order overlapping occurs in these orders. The AOTF FWHM is greater than the FSR, which will induce an additional contribution of the adjacent orders to the scanned order. The resolution of SOIR varies from order to order, with a value of about $0.11 \mathrm{~cm}^{-1}$ in diffraction order 101 to $0.21 \mathrm{~cm}^{-1}$ in order 194.

[8] The slit of SOIR is rectangular, with a viewing angle of $2^{\prime}$ in the spectral direction, and $30^{\prime}$ in the spatial direction. The apparent size of the Sun at Venus is 44', which ensures that the slit will remain within the solar disc. The detector counts 320 pixels in the spectral direction and 256 pixels in the spatial direction called pixel rows further in the text. However, the light coming from the aperture only covers 32 pixel rows in the spatial direction. From onboard measurements, it has been observed that on these 32 pixel rows, the side rows have a very bad signal-to-noise ratio. For that reason only the 24 central pixel rows are read. This has been applied to measurements which occurred after orbit 332 (19 March 2007). The pixel field of view varies between 0.03 and $0.06 \mathrm{~cm}^{-1}$ as a function of the pixel position and the diffraction order.

[9] Due to telemetry constraints, SOIR can only send 8 measurement packets per second. The AOTF and the electronics of SOIR limit the number of orders to be measured to 4 orders per second. With all these constraints, six different cases have been defined to sound Venus' atmosphere. The pixel rows are summed up and groups of pixel rows have been defined. They are summarized in Table 1.

[10] As an example, and throughout the following text, we will consider the $2 \times 12$ pixel rows case. As 4 diffraction orders can be measured successively during one second, each order is scanned during $250 \mathrm{~ms}$, and the same order is scanned once in every second. Two groups of lines are defined, each group results of the sum of 12 pixel rows on the detector. This operation improves also the signal-tonoise ratio. Typical values for the signal-to-noise ratio range between 500 and 3000. As the SOIR instrument is able to measure at best 4 diffraction orders almost simultaneously during one solar occultation, 4 different wave number ranges and therefore various species can be probed almost simultaneously.

\section{Solar Occultation Technique}

[11] The solar occultation technique used by SOIR allows the derivation of unique information about the vertical structure and composition of the Venus mesosphere [Vandaele et al., 2008]. SOIR is looking toward the Sun and records spectra on a one second cycle basis. Solar occultations occur when the line of sight of the instrument crosses the atmosphere of Venus. The projection of the center of the slit on the limbs during each single measurement defines the tangent altitude. Because the spacecraft is moving along its orbit, the instrument sounds the atmosphere of the planet at different tangent altitudes, see Figure 1. Two different configurations can be observed: the ingress case, when the tangent altitude decreases with time, and the egress case, when the tangent altitude increases with time. For the sake of simplicity, only the ingress case will be described here. 


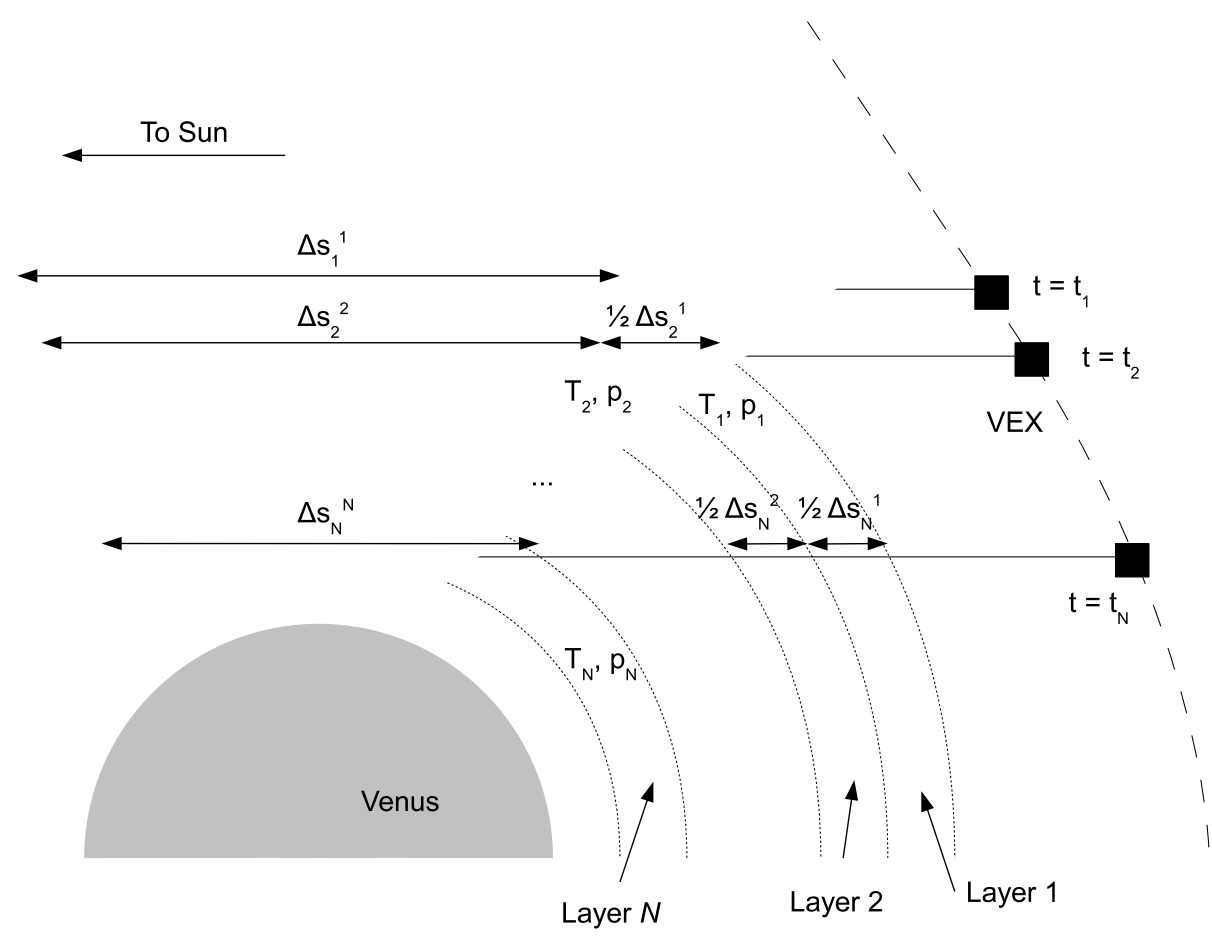

Figure 1. Onion-peeling definition while performing a solar occultation. The tangent altitude of each measurement defines a layer. The layers are spherical, and the atmospheric parameters such as the temperature $T_{i}$, pressure $p_{i}$, and partial pressure of a given species are considered to be constant within each layer $i$. The light path length within layer $i$ of the measurement $j$ (having its tangent altitude in layer $j$ ) is denoted $\Delta s_{i}^{j}$.

The egress case may be considered as ingress with the time scale reversed.

[12] The instrument is turned on and, after a precooling phase to ensure that the detector temperature has reached its operating value of about $70 \mathrm{~K}$, it starts recording solar spectra before the line of sight crosses the atmosphere. It is assumed that the atmosphere of Venus extends up to $220 \mathrm{~km}$ in altitude [Hedin et al., 1983]. This procedure starts early enough, corresponding to tangent altitudes well above $220 \mathrm{~km}$, to obtain an amount of at least 40 spectra taken outside the atmosphere. They define the reference Sun spectrum. A regression is calculated on each pixel of these recorded spectra to remove the small intensity drift observed. This operation reduces the systematic errors, and results in a higher signal-to-noise ratio. For tangent altitudes lower than $220 \mathrm{~km}$, the atmospheric transmittances are calculated by dividing the spectrum recorded at the current time by the reference Sun spectrum.

[13] The wave number calibration, i.e., converting pixel number of the detector to wave number using the position of known solar lines, includes a correction for the Doppler effect, as the speed of the satellite projected on the line of sight may vary during an occultation, but also from one orbit to the other. Indeed, the speed of the satellite often gets close to $+/-10 \mathrm{~km} / \mathrm{s}$, depending of the relative position of the Sun and VEX, which may result in slight displacements of the solar lines, used for the calibration.

[14] When SOIR points toward the Sun, the position of the slit with respect to Venus is set in order to have its spatial direction parallel to the limb of Venus, when the tangent altitude reaches $60 \mathrm{~km}$. The slit should remain as parallel as possible to the limb in order to have the smallest vertical resolution for each separate measurement. Since the VEX satellite is set into an inertial mode while performing a solar occultation, the slit rotates slightly, and does not remain parallel to the limb during the whole occultation. This tilting angle remains small, reaching maximum values in some occultations of about $10^{\circ}$, which slightly decreases the vertical resolution.

[15] The orbit of Venus Express is very eccentric with its apocenter, located above the north polar region, at an altitude of 180 to $250 \mathrm{~km}$ above the ground. The pericenter, above the south polar region, reaches $65,000 \mathrm{~km}$. For this reason, the vertical resolution of the measurement, which depends on the distance of the satellite to the limb, will also be dependent on the latitude of the measurement: high northern latitude $\left(60^{\circ}\right.$ to $\left.90^{\circ}\right)$ measurements have a very good vertical resolution, the layer thicknesses are small (from $200 \mathrm{~m}$ to $700 \mathrm{~m}$ ); measurements at lower latitudes $\left(-30^{\circ}\right.$ to $\left.60^{\circ}\right)$ have an average vertical resolution ranging from $700 \mathrm{~m}$ to $2 \mathrm{~km}$; southern latitudes $\left(-90^{\circ}\right.$ to $\left.-30^{\circ}\right)$ have a very poor vertical resolution, with layer thicknesses greater than $2 \mathrm{~km}$, up to $5 \mathrm{~km}$.

\subsection{Method Description}

[16] The analysis code is based on the ASIMUT program [Vandaele et al., 2008] and has been adapted in Matlab in order to improve the retrieval procedure, i.e., by allowing the determination of the temperature, and allowing more flexibility. The algorithm uses the onion peeling approach. 


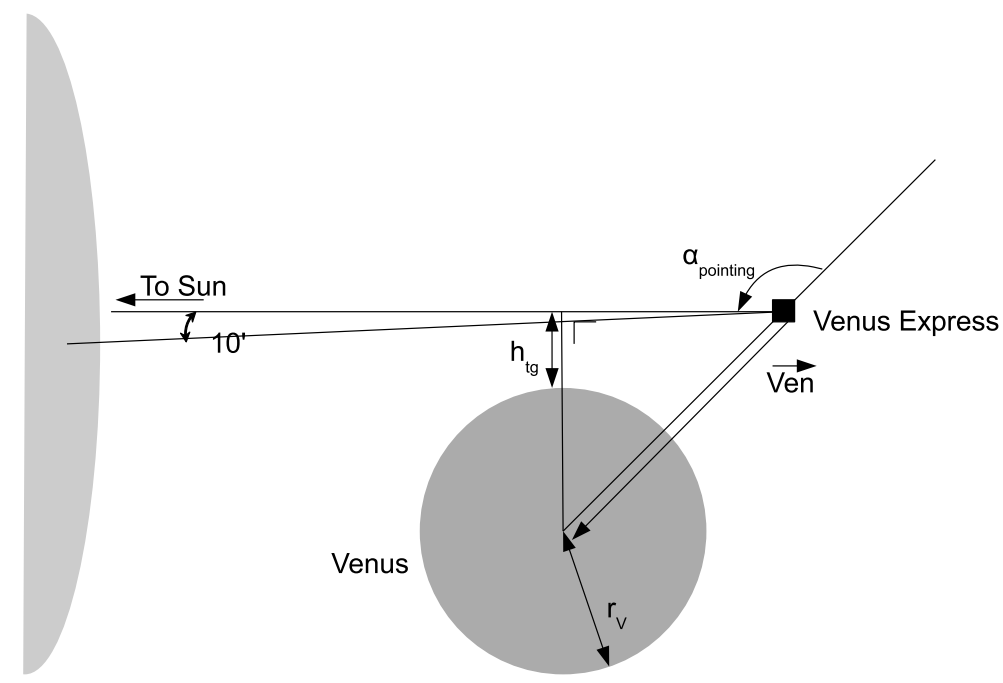

Figure 2. Pointing angles and distances definition. The distance between Venus' surface and VEX is $R_{V V}$. The tangent altitude is $H_{t g}$. The angle between the boresight of SOIR and the line linking the center of Venus and VEX is denoted $\alpha$. The SOIR instrument is pointing $10^{\prime}$ above the center of the Sun to ensure that the diffracted Sun remains within the slit for longer during the occultation [Mahieux et al., 2008].

This simplifies the problem, as for a given layer the physical properties only depend on the layers located below itself [Russel and Drayson, 1972]. The method will be described for the retrieval of the vertical density profile of a given molecule. In the cases of carbon dioxide and carbon monoxide retrievals, we will show how information can be obtained about molecular rotational temperature. The atti- tude of VEX is calculated using the Spice for Matlab routines developed by NASA Ancillary Information Facility (NAIF) [2009], and used by ESA for the Venus Express mission.

\subsection{Tangent Altitude and Ray Tracing}

[17] The tangent altitude of each measured transmittance of one occultation series defines the atmospheric layers used in the onion peeling method, see Figure 1. The tangent

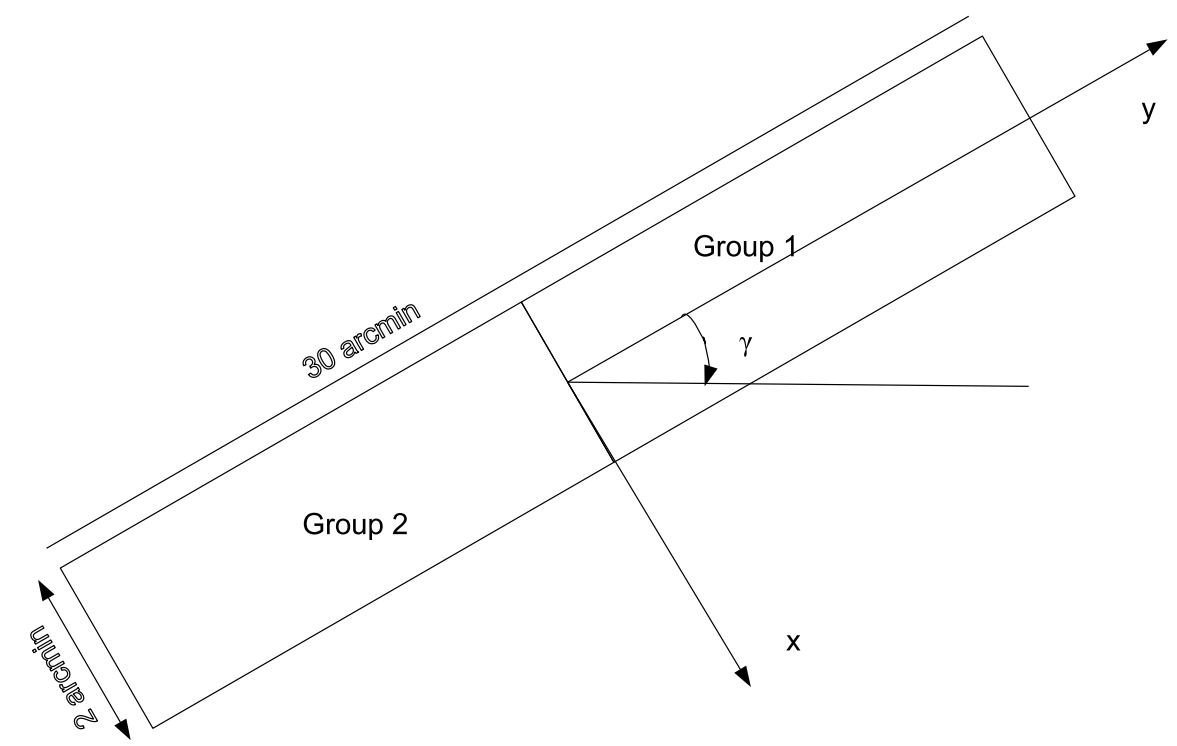

Figure 3. Representation of the slit. The slit has a width of $30^{\prime}$ and a height of $2^{\prime}$. In the binning configuration $2 \times 12$ pixel rows, it is divided in two groups. The axes depicted are the ones used by the Spice routine. The slit is tilted by an angle $\gamma$. The Sun is located along the $+z$ axis. The center of the slit is the origin of the $\mathrm{x}, \mathrm{y}$, and $\mathrm{z}$ coordinates. 
altitude is computed from the geometry of the pointing of the instrument relative to the Sun and the planet Venus as illustrated in Figure 2. The center of the projected slit is taken as a reference, see Figure 3. In this frame, the relation used to calculate the tangent altitude $\left(H_{t g}\right)$, when no refraction is taken into account, is

$$
H_{t g}=\cos (\pi-\alpha) \cdot R_{V V}
$$

where $R_{V V}$ is the distance from the satellite to the center of Venus and $\alpha$ is the pointing angle to the center of the projected slit, taking into account the $10^{\prime}$ depointing to the center of Sun, see Figure 2. The ray tracing calculation allows the determination of the tangent height and of the absorption path in each of the layers, taking into account the refraction of the light beam into the atmosphere. The refraction model is based on the measurements performed during the Magellan mission. The refraction is calculated as described by Vandaele et al. [2008]. The determination of the radiation path through the atmosphere, i.e., the path followed by the radiation reaching the instrument, requires that the planet's curvature and refraction be taken into account. The model is based on the ray-tracing program FSCATM [Gallery et al., 1983]. Some modifications were included in the implementation, essentially dealing with the determination of the index of refraction of the air of the planet. Integrated total density, integrated partial density of the molecules fitted, mean local temperature, integrated local pressure and path length are computed for each layer. They are also corrected by accounting for the height of the projected slit in the atmosphere at each measurement.

[18] As already stated, due to telemetry limitations, the detector is divided into several groups of lines, also called bins. The pointing directions are calculated for each of these bins separately. In our example, case $2 \times 12$, there are 2 bins, each made up of 12 detector rows. The size of the whole slit being $30^{\prime}$, along the spatial direction, by 2 ', along the spectral direction, the center of bin 1 is slightly depointed depending on the tilting angle $\gamma$, see Figure 3 .

\subsection{Absorption Cross Section and Transmittance Calculation}

[19] Molecular absorption cross sections (ACS) in each layer are calculated by a line by line procedure, extensively described by Vandaele et al. [2008], using spectroscopic parameters from Hitran 2008 [Rothman et al., 2009] adapted for the Venusian $\mathrm{CO}_{2}$-rich atmosphere. The absorption cross sections depend on the partial and total pressures, as well as on the temperature in each layer. The transmittance due to molecule $i$ in the layer $j$ is calculated using

$$
T_{i, j}=\exp \left\lfloor-n_{i, j} \cdot s_{j} \cdot A C S\left(n_{i, j}, t_{j}, p_{j}\right)\right\rfloor
$$

where $n_{i, j}$ is the density of the molecule $i$ in the layer $j, s_{j}$ is the path length within the layer $j$, and $t_{j}$ and $p_{j}$ are the temperature and the pressure in the layer $j$, obtained as explained in section 3.2 from the ray tracing algorithm. The transmittance $T_{L, \text { Molecular }}$ due to the molecular species present along the whole path corresponding to the tangent height $L$ is finally obtained by multiplying the absorbance of all molecules in all the above layers, the most outside layer being layer 1:

$$
T_{L, \text { Molecular }}=\prod_{j=1}^{L} \prod_{i=1}^{n_{\text {molecules }}} T_{i, j} .
$$

[20] Aerosols, which are present in the Venus atmosphere in large quantities [Esposito, 1983; Lane and Opstbaum, 1983], also have a characteristic signature. In the infrared region probed by SOIR their signature is large, but broad and without fine structures [Wilquet et al., 2009]. Their influence on the observed spectra is to decrease the mean transmittance level. This effect is more pronounced as the line of sight goes deeper into the atmosphere.

[21] The impact of aerosols is considered by representing their contribution to the transmission by a second degree polynomial on the wave number. For layer $L$, the aerosol contribution can be written as

$$
T_{L, \text { Aerosols }}=a_{L}+\left(\omega_{n}-\omega_{n_{0}}\right) \cdot b_{L}+\left(\omega_{n}-\omega_{n_{0}}\right)^{2} \cdot c_{L}
$$

where $a_{L}, b_{L}$ and $c_{L}$ are the polynomial coefficients, $\omega_{n}$ is the wave number, $\omega_{n_{0}}$ is the central wave number of the scanned order. The aerosol extinction can be calculated from the parameters $a_{L}$ [Bingen et al., 2003]. The results have already been discussed by Wilquet et al. [2009], and will be deeper analyzed in a future publication (V. Wilquet et al., Aerosol characterization and climatology observed by the SOIR instrument on board Venus Express, manuscript in preparation, 2010).

[22] Finally, the synthetic spectrum $I_{L}$, which will be compared to the one recorded by the instrument, is the solar spectrum attenuated by the effect of the atmospheric molecular species and aerosols, convolved by the instrumental function

$$
I_{L}=\operatorname{conv}(\underbrace{I_{\text {Sun }} \cdot T_{L, \text { Aerosols }} \cdot T_{L, \text { Molecular }}}_{\text {synthetic spectrum }}, \underbrace{\operatorname{Gauss}\left(\operatorname{Resol}_{S O I R}\right)}_{\text {instrument function }})
$$

with $I_{\text {Sun }}$ the Sun absorption cross section and $\operatorname{Gauss}\left(\operatorname{Resol}_{\text {SOIR }}\right)$ the instrument function with the spectral resolution function of SOIR [Mahieux et al., 2008].

[23] Even if the resolution of SOIR is good enough to resolve most of the atmospheric absorption lines, it remains a few factors larger than the width of the pressure broadened atmospheric absorption lines. Therefore the pressure cannot be deduced from the measured spectrum. This is mathematically illustrated by the convolution product in equation (5): the synthetic spectrum has a FWHM of about $0.001 \mathrm{~cm}^{-1}$ to $0.01 \mathrm{~cm}^{-1}$, while the resolution of SOIR is about $0.15 \mathrm{~cm}^{-1}$.

\subsection{Order Addition}

[24] The bandwidth of SOIR's AOTF, used for the diffraction order selection, is larger than the free spectral range of the echelle grating. To correctly simulate the spectra measured by the spectrometer, the contribution of the adjacent orders also has to be taken into account. Usually, the two first adjacent orders and the central order are considered to form most of the observed transmittance. In some cases, however, when very strong lines are present in 

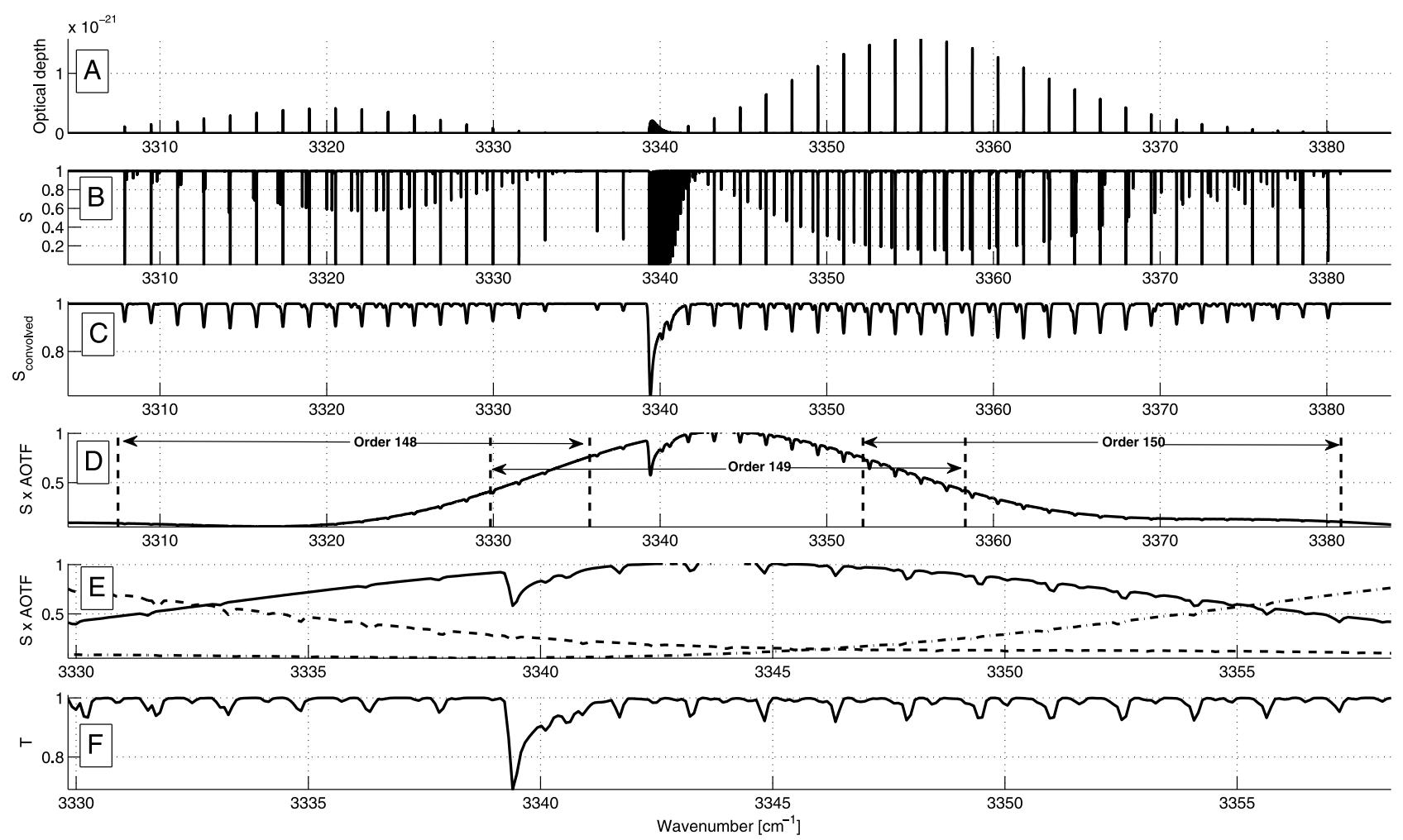

Figure 4. Procedure to simulate a SOIR spectrum. (a) The absorption cross section of $\mathrm{CO}_{2}$ around $3340 \mathrm{~cm}^{-1}$. It has been calculated for one layer with atmospheric conditions at $90 \mathrm{~km}$. (b) The transmittance $\mathrm{T}$ of these lines after using the Beer-Lambert law. (c) The transmittance $\mathrm{T}$ after convolution by the instrument function. (d) The spectrum multiplied by the AOTF transfer function. The different diffraction orders are also indicated. The order overlap is clearly seen. (e) The contribution of the different orders: the bold line is the central order 149 , the dashed line is the order +1 , and the dashed-dotted line is the order -1 . (f) The sum of the contribution of the three considered orders. One can see that the role of the adjacent orders cannot be neglected, as absorption features of the adjacent order may have signification contributions.

adjacent orders located further away from the central order, it may be necessary to consider a larger number of adjacent orders. Usually, 3 diffraction orders are taken into account. The contribution from the adjacent orders is calculated using

$$
T=\frac{\sum_{i=-n_{\text {orders }}}^{n_{\text {orders }}} A O T F_{i} \cdot I_{L}}{\sum_{i=-n_{\text {orders }}}^{n_{\text {orders }}} A O T F_{i} \cdot I_{\text {Sun }}}
$$

where $T$ is the transmittance, $n_{\text {orders }}$ is the number of adjacent orders considered, $A O T F_{i}$ is the values of the AOTF transfer function in the order $i$ and $I_{i}$ is the convoluted absorbance of the molecules and aerosols absorbing in order $i$ [Mahieux et al., 2009]. The whole procedure for constructing a synthetic spectrum is depicted in Figure 4.

\section{Retrieval Algorithm}

[25] The optimal estimation (OE) method developed by Rodgers [Rodgers, 1990, 2000] has been implemented to inverse the observed transmittances. All transmittances, corresponding to one occultation series considered after the selection procedure, are inversed in one go.

\subsection{Implementation of the OE Algorithm}

[26] The transmittance in a given layer $L$ is given by where $T_{L}$ is the transmittance at the layer $L, A O T F_{p}$ is the

$$
\begin{aligned}
T_{L} & =\frac{\sum_{p=-n_{\text {orders }}}^{n_{\text {orders }}} A O T F_{p} \cdot \operatorname{conv}\left\{I_{\text {Sun }} \cdot T_{L, \text { Aerosols }} \cdot \prod_{j=1}^{L} \prod_{i=1}^{n_{\text {molecules }}} \exp \left[-n_{i j} \cdot s_{j} \cdot \operatorname{ACS}\left(S_{i j}\left(n_{i j}, t_{j}, \omega_{n}^{\prime} j\right)\right], \operatorname{Gauss}\left(\sigma_{S O I R}\right)\right\}\right.}{\sum_{p=-n_{\text {orders }}}^{n_{\text {orders }}} \operatorname{AOTF} F_{p} \operatorname{conv}\left\{I_{\text {Sun }}, \operatorname{Gauss}\left(\sigma_{S O I R}\right)\right\}} \\
T_{L, \text { Aerosols }} & =a_{L}+\left(\omega_{n}-\omega_{n_{0}}\right) \cdot b_{L}+\left(\omega_{n}-\omega_{n_{0}}\right)^{2} \cdot c_{L} \\
\omega_{n}^{\prime} j & =\omega_{n}+d_{j}
\end{aligned}
$$


modified AOTF transfer function, adapted on the $n_{A O T F}$ points and translated of a value $d_{A O T F}, d_{i}$ is the wave number shift of layer $j$ and $\sigma_{S O I R}$ is the resolution of the instrument. In this equation, $n_{i j}, t_{j}, a_{L}, b_{L}, c_{L}, A O T F_{p}, d_{A O T F}$ and $d_{j}$ are unknown variables.

[27] In order to fit $T_{L}$ to the measured spectra, the problem is written in the form

$$
y=F(x, b)+\varepsilon
$$

where $y$ is the measurement vector (the measured transmittances), $x$ is the state vector (all unknown variables to be retrieved, f.e. the vertical density profiles), $b$ represents the additional parameters used by the forward model, whose function is $F$. The forward function $F$ describes the complete physics of the measurement, including the description of the instrument. $F$ is the set of $L$ functions $T_{L}$ described in equation (7). $\varepsilon$ represents the noise on the measurement.

[28] Let us consider the retrieval of the vertical profiles of $n_{\text {molecules }}$ from a series of $n_{\text {spectra }}$ transmittances acquired during one occultation. The $n_{\text {spectra }}$ spectra have defined a structured atmosphere composed of $m_{\text {layer }}=n_{\text {spectra }}$ layers (see Figure 1), whose boundaries correspond to the tangent heights of each measurement. The state vector contains all the variables fitted during the retrieval procedure. These variables are the $a, b$ and $c$ parameters of the aerosol contribution $\left(3 \times m_{\text {layer }}\right.$ variables $)$, and the logarithm of the molecular densities of the targeted species in all the defined layers $\left(n_{\text {molecules }} \times m_{\text {layer }}\right.$ variables $)$. The temperature in each layer may also be fitted ( $m_{\text {layer }}$ variables). Even if the line intensities of all molecules are temperature dependent, the temperature is only fitted for molecules having regularly spaced absorption lines or absorption lines close to each others, such as $\mathrm{CO}$ or $\mathrm{CO}_{2}$. Moreover a wave number shift can be introduced and fitted for each spectrum $\left(m_{\text {layer }}\right.$ variables) to improve the matching of the absorption lines positions from the spectroscopic database and the observed position. The AOTF transfer function may be fitted too: First, a slight variation is allowed on several points, usually around 40 , to improve the quality of the fit ( $n_{A O T F}$ variables); Second, the AOTF transfer function may also be translated along the wave number axis, to correct for possible deviations of the wave number - AOTF frequency relation [Mahieux et al., 2008] (1 variable). It leads to a total number of variables of $n_{\mathrm{var}}=\left(5+n_{\text {molecules }}\right) \cdot m_{\text {layer }}+n_{\text {AOTF }}+1$.

[29] The Rodgers formalism solves the problem written in equation (8) by starting from an a priori value of the variable $x$ iterating on the following equation:

$$
\begin{aligned}
x_{k+1}= & x_{k}+\left(S_{a}^{-1}+K_{k}^{T} S_{\varepsilon}^{-1} K_{k}\right)^{-1} \\
& \cdot\left[K_{k}^{T} S_{\varepsilon}^{-1}\left(y-F\left(x_{k}\right)\right)-S_{a}^{-1}\left(x_{k}-x_{a}\right)\right]
\end{aligned}
$$

where $x_{k}$ are the state vector values at iteration $k, S_{a}$ is the covariance matrix of the fitted parameters, $S_{\varepsilon}$ is the measurement error matrix, $K_{k}$ is the Jacobian of the problem at iteration $k, y$ contains the measured spectra, $F$ is the forward model of equation (8) and $x_{a}$ is the a priori state vector.

[30] The covariance matrix $S_{a}$ contains the allowed variability of each variable:

$$
S_{a}=\varepsilon\left\{\left(x-x_{a}\right)\left(x-x_{a}\right)^{T}\right\}
$$

where $x_{a}$ is the a priori state vector and $x$ is the solution of the problem. Non diagonal terms are added for the covariance of the densities, temperature, wave number shift and AOTF transfer function variations. A Gaussian dependence is used to account for correlations between the different points where the AOTF transfer function is fitted and to ensure a final smooth AOTF transfer function. They are defined as

$$
S_{a}^{\omega}(i, j)=\sqrt{S_{a}^{\omega}(i, i) \cdot S_{a}^{\omega}(j, j)} \cdot \exp \left[-\left(\frac{\omega_{n_{i}}-\omega_{n_{j}}}{l_{\omega}}\right)^{2}\right]
$$

where $S_{a}^{\omega}$ is the submatrix of $S_{a}$ corresponding to the AOTF transfer function fit, $\omega_{n_{i}}$ is the wave number position of point $i, l_{c}$ is the correlation length [Vandaele et al., 2006]. The correlation length has been chosen to be a fifth of the diffraction order width for the AOTF transfer function. In the case of the densities, temperature and wave number shift, the coefficients are

$$
S_{a}^{n, t, d}(i, j)=\sqrt{S_{a}^{n, t, d}(i, i) \cdot S_{a}^{n, t, d}(j, j)} \cdot \exp \left[-\left(\frac{z_{i}-z_{j}}{l_{z}}\right)^{2}\right]
$$

where $S_{a}^{n, t, d}$ is the submatrix of $S_{a}$ corresponding to the density, temperature or wave number shift variables, $z_{i}$ is the altitude of point $i$ and $l_{z}$ is the correlation length, defined as the height of the projected slit at the tangent point. In the case of the aerosols contribution only diagonal terms are considered. $S_{a}$ is a square matrix of size $n_{\mathrm{var}}$.

[31] The measurement error matrix $S_{\varepsilon}$ contains the estimated errors calculated from the signal-to-noise ratio. $S_{\varepsilon}$ is not square and has a size of $n_{\omega_{n}} \cdot m_{\text {layer }}$, where $n_{\omega_{n}}$ is the number of wave number points in each interval used for the fit.

[32] The Jacobian matrix $K$ contains the first derivatives of the forward model with relation to all the state vector variables. The derivatives

$$
\frac{\partial T}{\partial a_{L}}, \frac{\partial T}{\partial b_{L}}, \frac{\partial T}{\partial c_{L}}, \frac{\partial T}{\partial n_{i j}}, \frac{\partial T}{\partial t_{j}}, \frac{\partial T}{\partial d_{j}}, \frac{\partial T}{\partial n_{A O T F}}, \frac{\partial T}{\partial d_{A O T F}}
$$

are easily computed. They are all derived analytically, except for the displacement derivatives $\frac{\partial T}{\partial d_{j}}$, which are calculated numerically.

[33] The sub matrices of $K, \frac{\partial T}{\partial n_{i j}}, \frac{\partial T}{\partial t_{j}}$ and $\frac{\partial T}{\partial d_{i}}$, are inferior triangular matrices because of the onion peeling procedure. $\frac{\partial T}{\partial d_{A O T F}}$ is a vector, as $\frac{\partial T}{\partial a_{L}}, \frac{\partial T}{\partial b_{L}}, \frac{\partial T}{\partial c_{L}}$ which have nonzero values only for a given layer. $\frac{\partial T}{\partial n_{A O T F}}$ is a full matrix. $K$ has a size of $n_{\mathrm{var}} \times\left(n_{\omega_{n}} \cdot m_{\text {layer }}\right)$. The vectors $x_{k}, x_{a}, F\left(x_{i}\right)$ and $y$ contain the state vector variables at step $k$, the a priori values of the variables $x_{k}$, the calculated transmittance at step $k$, and the $n_{\text {spectra }}$ observed spectra, respectively. The vectors $x_{k}, x_{a}$ have a length of $n_{\mathrm{var}}$, while the vectors $F\left(x_{i}\right)$ and $y$ have a length of $\left(n_{\omega_{n}} \cdot m_{\text {layer }}\right)$.

[34] The convergence of the algorithm is achieved when the following criterions are both satisfied

$$
\begin{gathered}
\left(x^{t}-x^{t-1}\right) \cdot\left(S_{a}^{-1}+K^{\prime} \cdot S_{e}^{-1} \cdot K\right)^{-1} \cdot\left(x^{t}-x^{t-1}\right)<0.001 \cdot n_{\mathrm{var}} \\
\left(F^{t}-F^{t-1}\right) \cdot\left(S_{\varepsilon} \cdot K \cdot S_{a} \cdot K^{\prime} \cdot S_{\varepsilon}\right) \cdot\left(F^{t}-F^{t-1}\right)<0.001 \cdot n_{\omega_{n}} \cdot m_{\text {layer }}
\end{gathered}
$$


where $x^{t}$ and $F^{t}$ are the state vector and the function described in equation (10), respectively.

[35] The error calculation is done using the relations

$$
\begin{aligned}
\hat{x}-x & =\left(A-I_{n}\right) \cdot\left(x-x_{a}\right)+G \cdot \varepsilon \\
G & =\left[\left(S_{a}^{-1}+K^{T} \cdot S_{\varepsilon}^{-1} \cdot K\right) \cdot K^{T} \cdot S_{\varepsilon}^{-1}\right]^{-1} \\
A & =G \cdot K
\end{aligned}
$$

where $\hat{x}-\mathrm{x}$ is the error vector, $x$ is the solution at convergence and $\hat{x}$ is the exact solution, $I_{n}$ is a unity matrix having the same size as $A$ and $\varepsilon$ is the error vector used to build $S_{\varepsilon}$. The covariance of the error vector is built by considering two sources, namely the a priori covariance $S_{s}$ and the retrieval noise covariance $S_{m}$ :

$S_{s}=\left(S_{a}^{-1}+K^{T} \cdot S_{\varepsilon}^{-1} \cdot K\right)^{-1} \cdot S_{a}^{-1} \cdot\left(S_{a}^{-1}+K^{T} \cdot S_{\varepsilon}^{-1} \cdot K\right)^{-1}$

$S_{m}=\left(S_{a}^{-1}+K^{T} \cdot S_{\varepsilon}^{-1} \cdot K\right)^{-1} \cdot K^{T} \cdot S_{\varepsilon}^{-1} \cdot K \cdot\left(S_{a}^{-1}+K^{T} \cdot S_{\varepsilon}^{-1} \cdot K\right)^{-1}$.

\subsection{Fitting Procedure}

[36] For a given occultation and a given diffraction order, the spectroscopic parameters of the different species to retrieve must be supplied, as well as the wave number range on which they will be fitted. More than one isotopologue for each species may be fitted simultaneously. The altitude range is automatically determined, but may also be imposed by the user.

[37] The algorithm returns the fitted values of all the parameters defined earlier. The user has the choice to use the a priori atmospheric parameters derived from the atmosphere model, or to use the ones derived from another fitting procedure, for example a quasi simultaneous $\mathrm{CO}_{2}$ inversion.

\subsection{Predetermination of the Useful Altitude Range}

[38] We have developed an automatic procedure to determine the useful altitude range of the retrieval of one given occultation. Usually, atmospheric spectra are recorded at tangent altitudes starting around $220 \mathrm{~km}$ and down to $60 \mathrm{~km}$. However, the spectra corresponding to the higher altitudes usually do not contain any absorption features, but provide a good indication of the noise level of the measurements, and spectra corresponding to the lowest altitudes are often saturated due to too high atmospheric absorption as detailed in the following.

[39] The first spectrum considered for the retrieval corresponds to the emergence of the monitored absorption structures. Only the wave number range on which the retrieval is performed is considered. The maximum $\left(I_{\max }\right)$, minimum $\left(I_{\min }\right)$ and mean $\left(I_{\text {mean }}\right)$ values of the transmittance are computed on this window for each atmospheric spectrum. The depth of the strongest observed line $\left(I_{\text {diff }}\right)$ is computed by subtracting the minimum value from the maximum value $\left(I_{d i f f}=I_{\max }-I_{\min }\right)$. At high altitudes, usually above $180 \mathrm{~km}$, just before the emergence of the absorption features, only noise is measured, and $I_{\text {diff }}$ provides a good estimate value for it. A signal to noise value $\left(\overline{S N R_{180-220}}\right)$ representative of these high altitudes is cal- culated by considering the average values of the signal and of the noise between $220 \mathrm{~km}$ and $180 \mathrm{~km}, \overline{I_{\text {mean }}}$ and $\overline{I_{\text {diff }}}$,

$$
S N R_{180-220}=\frac{\overline{I_{\text {mean }}}}{\overline{I_{\text {diff }}}} .
$$

[40] The first spectrum to consider for the retrieval procedure corresponds to the altitude when the absorption structures are seen above the noise. From trials, a factor of 0.002 has been introduced, thus the first spectrum is defined for

$$
\frac{I_{\text {mean }}}{I_{\text {diff }}}<0.002 \cdot S N R_{180-220}
$$

From this altitude and below, spectral structures are seen in the spectra.

[41] The lower bound of the altitude range is defined when saturation occurs: the atmospheric absorption lines have transmittances reaching zero values at their center, before convolution by the instrument resolution function. From this altitude, the information contained in the spectra becomes useless, and reliable retrievals cannot be made.

[42] The criteria used for the selection of first and last spectra are clearly demonstrated when plotting the quantity $\frac{I_{\text {mean }}}{I_{\text {diff }}}$ as a function of the altitude, as illustrated in Figure 5. The slope radically changes at two well defined altitudes. Values of $\frac{I_{\text {man }}}{I_{\text {diff }}}$ are almost constant above the altitude of point 2 on Figure $5 \mathrm{c}$ corresponding to the appearance of the absorption features as illustrated by Figures $5 \mathrm{a}$ and $5 \mathrm{~b}$, corresponding to one spectrum without absorption structures and one with them, respectively. The altitude of the last spectrum to be included in the retrieval, point 3 on Figure $5 \mathrm{c}$, is obtained at the second change in slope. Below this altitude, most of the absorption lines are saturated - at infinite resolution - and the surface under the structures seen in the convolved spectrum recorded by the instrument are no longer proportional to the density of the absorbing species.

[43] Saturation may be observed if the transmittance of a spectral line reaches values close to zero. In that case, all the information contained in the observed spectral line is lost, as the shape of the line does not vary with increasing densities. It is not directly observed on the spectra measured by SOIR, as the resolution of the instrument is much larger than the width of the observed spectral lines. Detection procedures of such events have been developed, to avoid meaningless density profiles. All absorption lines having a transmittance (at infinite resolution) lower than 0.15 are considered as saturated (J. van der Auwera, private communication, 2010). The transmittance before convolution and order addition $\tilde{T}_{L}\left(\omega_{n}\right)$ is defined as

$$
\tilde{T}_{L}\left(\omega_{n}\right)=\prod_{j=1}^{L} \prod_{i=1}^{n_{\text {molecules }}} \exp \left[-n_{i j} \cdot s_{j} \cdot A C S_{i j}\left(n_{i j}, t_{j}, \omega_{n_{j}}\right)\right] .
$$

[44] If saturation occurs, two actions are taken: (1) all the points $\omega_{n}^{*}$ for which we have $\tilde{T}_{L}\left(\omega_{n}^{*}\right)<0.15$ are removed from the fitted wave number range and (2) the spectrum of layer $j^{*}$ at iteration $k$ of the Rodgers algorithm is said to be 


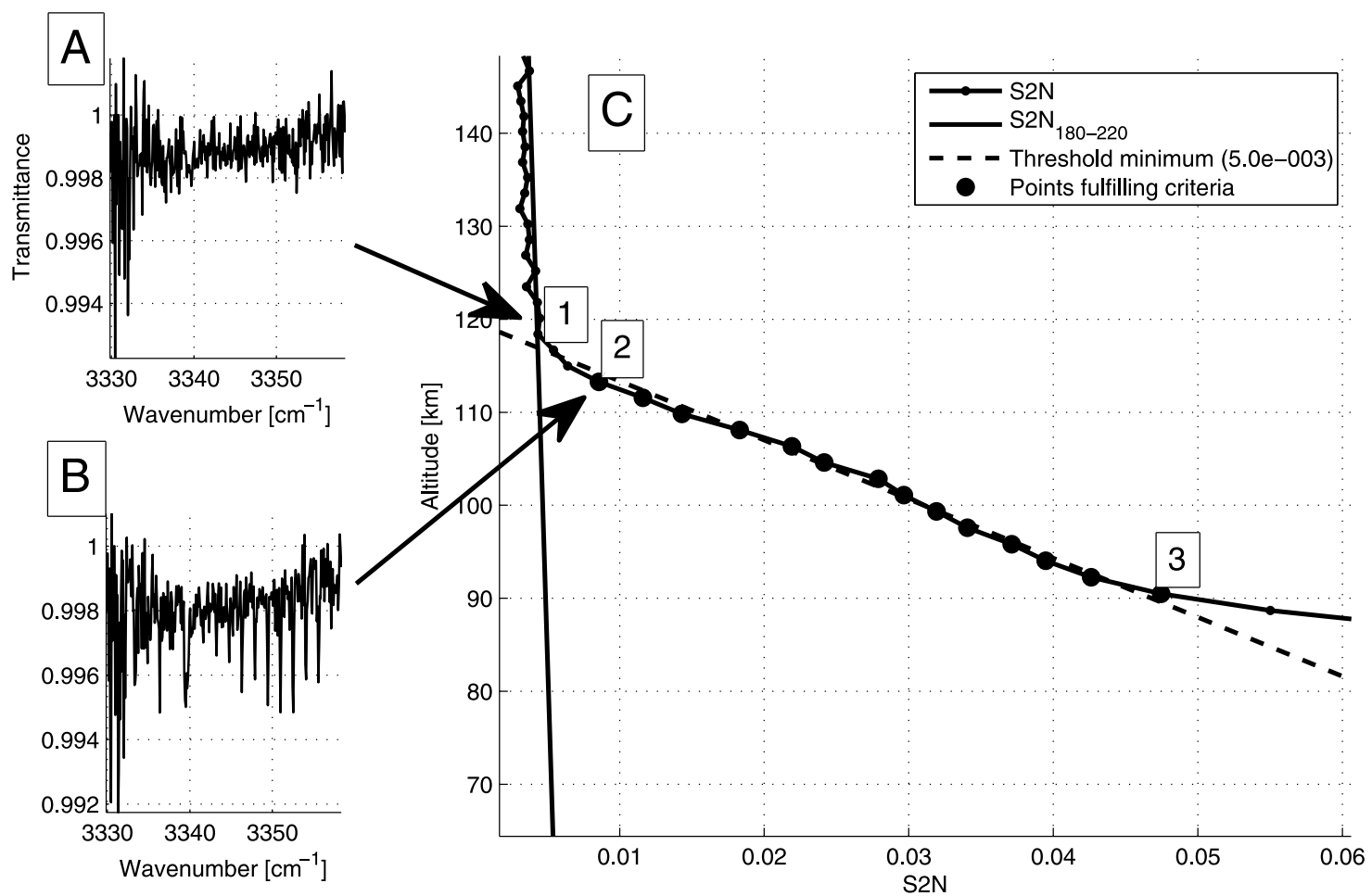

Figure 5. Determination of the altitude range. The altitude range is determined by studying the quotient $I_{\text {mean }} / I_{\text {diff }}$, with $I_{\text {mean }}$ being mean value of the spectrum on the interval fitted and $I_{\text {diff }}$ being the maximum less the minimum value on the interval. Figure $5 \mathrm{c}$ depicts its variation as a function of altitude. At high altitude, above point 1 (see spectrum in Figure $5 \mathrm{a}$ ), $I_{\text {mean }} / I_{\text {diff }}$ is a majoring value of the noise level. When the absorption structures start appearing the spectra, at point 2 (see spectrum in Figure $5 b$ ), an inflection point is observed in the curve. It is observed that the second inflection point (point 3 ) corresponds to the altitude when the absorption lines are completely saturated.

saturated if more than 40 percent of the absorption lines coming from the central order are saturated, or 40 percent of the detector is covered by saturated lines. In that case, the altitude range is modified to suit the saturation criterion: all the layers $j$ located under and including the current layer $j^{*}$ are excluded from the retrieval, i.e., for $j^{*} \leq j \leq m_{\text {layer }}$. To that end, the corresponding lines and columns are removed from the $S_{a}, K, S_{\varepsilon}, Y, F, x_{k}$ and $x_{a}$ matrices or vectors. That condition is evaluated at each step of the $\mathrm{OE}$ algorithm.

[45] However, the aerosol background can be retrieved for the layers in which saturation occurs, if the saturated lines are removed from the wave number fitted range. The variables $a, b$ and $c$ of the aerosol background are thus retrieved on the entire occultation, while the density, temperature and displacement are only retrieved in the non saturated altitude range.

\subsection{Model of the Atmosphere}

[46] In this work, we have used temperature and pressure vertical profiles from the VIRA model for altitudes up to $100 \mathrm{~km}$ [Seiff et al., 1985]. For higher altitudes (from $140 \mathrm{~km}$ and upward), data were taken from the model of Hedin et al. [1983] as suggested by MuellerWodarg and Tingle [2008]. The transition between the two data sets was performed by splines interpolating the temperature and reconstructing the pressure through the hydrostatic law.

\subsection{Temperature Dependence}

[47] SOIR spectra are sensitive to the atmospheric temperature through its influence on the strength of the absorption features of, for example, $\mathrm{CO}$ or $\mathrm{CO}_{2}$. Temperature will influence the overall shape of one specific vibrational band, as shown in Figure 6. Each peak belongs to a given rotational transition $\mathrm{J}$. If temperature increases the position of the band absorption maximum will move from low $\mathrm{J}$ lines to higher $\mathrm{J}$ lines, as the distribution of line intensities for different rotational transition changes. From the overall shape, temperature can then be derived even if some of the information contained in this shape disappears because of the curvature of the AOTF transfer function, as illustrated in Figure 6.

[48] This approach leads to the determination of the rotational temperature of the gas in one vibrational band. Local thermodynamical equilibrium (LTE) needs to be satisfied in order to assimilate the rotational temperature to the kinetic temperature, which may not be necessarily the fact [Gilli et al., 2009]. However, the non-LTE effects only weakly affect ground state rotational transition bands (M. A. Lopez-Valverde, private communication, 2010).

[49] The shape of the AOTF function will thus influence the temperature retrieval, as a good knowledge of the function is needed in order to correctly build the synthetic spectrum. However, the correction of the AOTF function using the $n_{A O T F}$ points as described in section 4.1 will only 

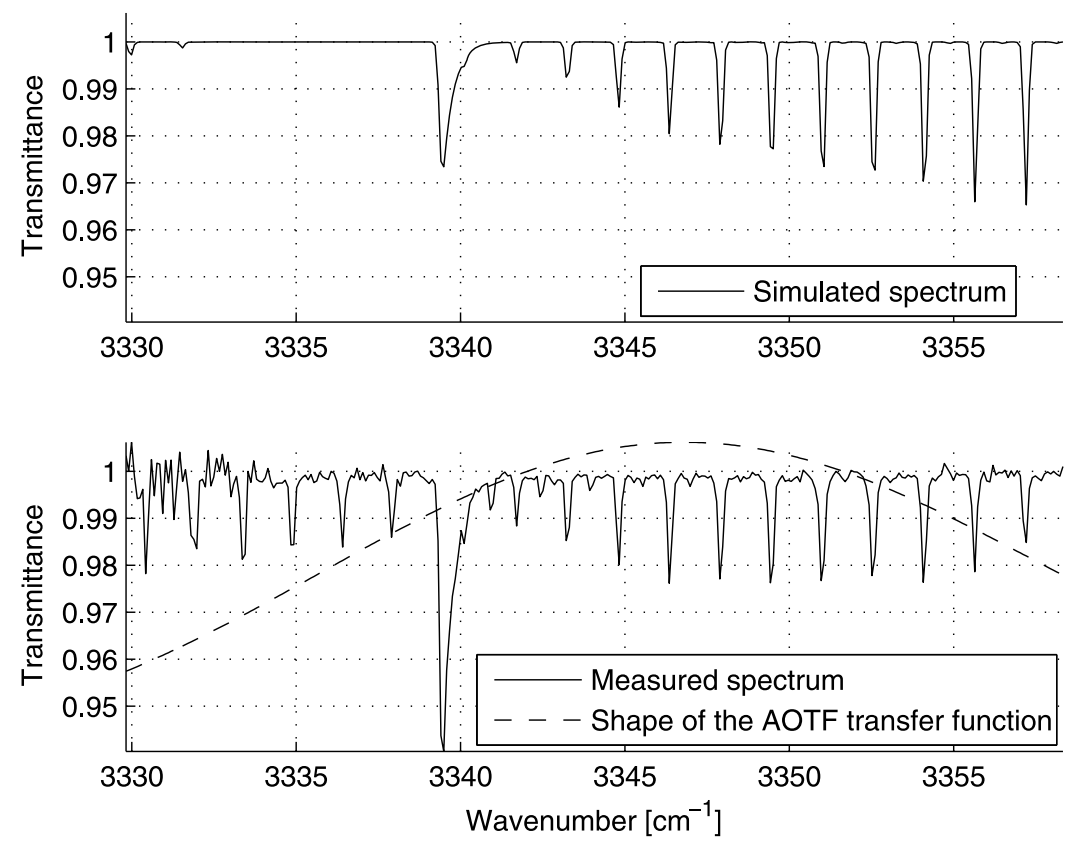

Figure 6. Temperature dependency. The temperature information is influenced by the shape of the AOTF transfer function. (top) $\mathrm{A} \mathrm{CO}_{2}$ spectrum in diffraction order 149 , simulated for a layer (atmospheric conditions: altitude of $110 \mathrm{~km}$, pressure of $0.152 \mathrm{~Pa}$, temperature of $181.2 \mathrm{~K}$, total density of $0.1 \times 10^{-4} \mathrm{~mol} / \mathrm{m}^{3}$, volume mixing ratio of 0.965 , path length of $200 \mathrm{~km}$ ) but without order addition nor contribution of the AOTF transfer function. It is clearly seen that the maximum of absorption of the band is located around $3347 \mathrm{~cm}^{-1}$. (bottom) The measured spectrum and the shape of the AOTF function. It is obvious that the maximum of the measured transmittance has been displaced closer to the maximum of the AOTF transfer function.

locally modify the transfer function, and thus not the overall shape.

\subsection{Wave Number Scale Definition}

[50] Using the theoretical relations of the echelle grating, a linear relationship between the wave number, the order and the pixel number can be defined [Schroeder and Hilliard, 1980; Nevejans et al., 2006; Mahieux et al., 2008]

$\left\{\begin{array}{l}d\left(\sin \theta_{i}+\sin \theta_{m}\right)=m \cdot \lambda \\ \lambda=10^{-2} / \omega_{n} \\ \text { pixel }=f\left(\theta_{m}\right)\end{array} \Rightarrow\right.$ pixel $=f\left[\arcsin \left(\frac{m \cdot 10^{-2}}{d \cdot \omega_{n}}-\sin \theta_{i}\right)\right]$

where $\theta_{i}$ is the incident angle on the grating, $\theta_{m}$ is the refracted angle on the grating, $m$ is the diffraction order, $\lambda$ is the wavelength, $d$ is the groove spacing of the echelle grating and $f$ is a linear function linking the diffracted angle and the pixel number.

[51] The calibration has been performed by comparing the positions of selected solar lines observed by SOIR outside the Venus atmosphere with a reference atlas of solar lines [Altieri et al., 2009], taking into account a correction applied to the observed solar lines for the Doppler effect induced by the motion of Venus Express relative to the Sun. Indeed, the satellite is orbiting around Venus at a speed which is varying significantly. The speed at apogee may reach absolute values of $10 \mathrm{~km} / \mathrm{s}$ relative to Venus. The speed vector has to be projected onto the line of sight of the SOIR instrument.
The sign of the speed may be positive or negative, depending of the satellite movement direction relative to the Sun.

$$
\omega_{n}^{\prime}=\omega_{n} \cdot\left(1+\frac{v_{V E X}}{c}\right)
$$

where $\omega_{n}$ is the wave number position of the line - taken from the solar atlas, $v_{V E X}$ is the speed of the Venus Express satellite relative to Venus projected onto the line of sight of the instrument, $c$ is the speed of light and $\omega_{n}^{\prime}$ is the wave number corrected for the Doppler effect. The rotation of the planet itself is not taken into account, as its speed is very low: about $1.811 \mathrm{~m} / \mathrm{s}$ at the equator. The speed of the planet Venus around the Sun projected onto the line of sight may be neglected during an occultation, as the eccentricity of the orbit of Venus is very small ( 0.00677323$)$.

[52] After these corrections, it has been observed that small variations remain when considering the coincidence of the observed and database absorption lines. The justification comes from small temperatures variations within the instrument that may induce such variations to the above described calibration. The residual is fitted using the relation

$$
\omega_{n}^{\prime}=\omega_{n}+\left(e+f \cdot\left(\omega_{n}-\omega_{n 0}\right)\right)
$$

where $e$ and $f$ are the coefficients of a first-order polynomial. These two variables are fitted on the whole occultation, 

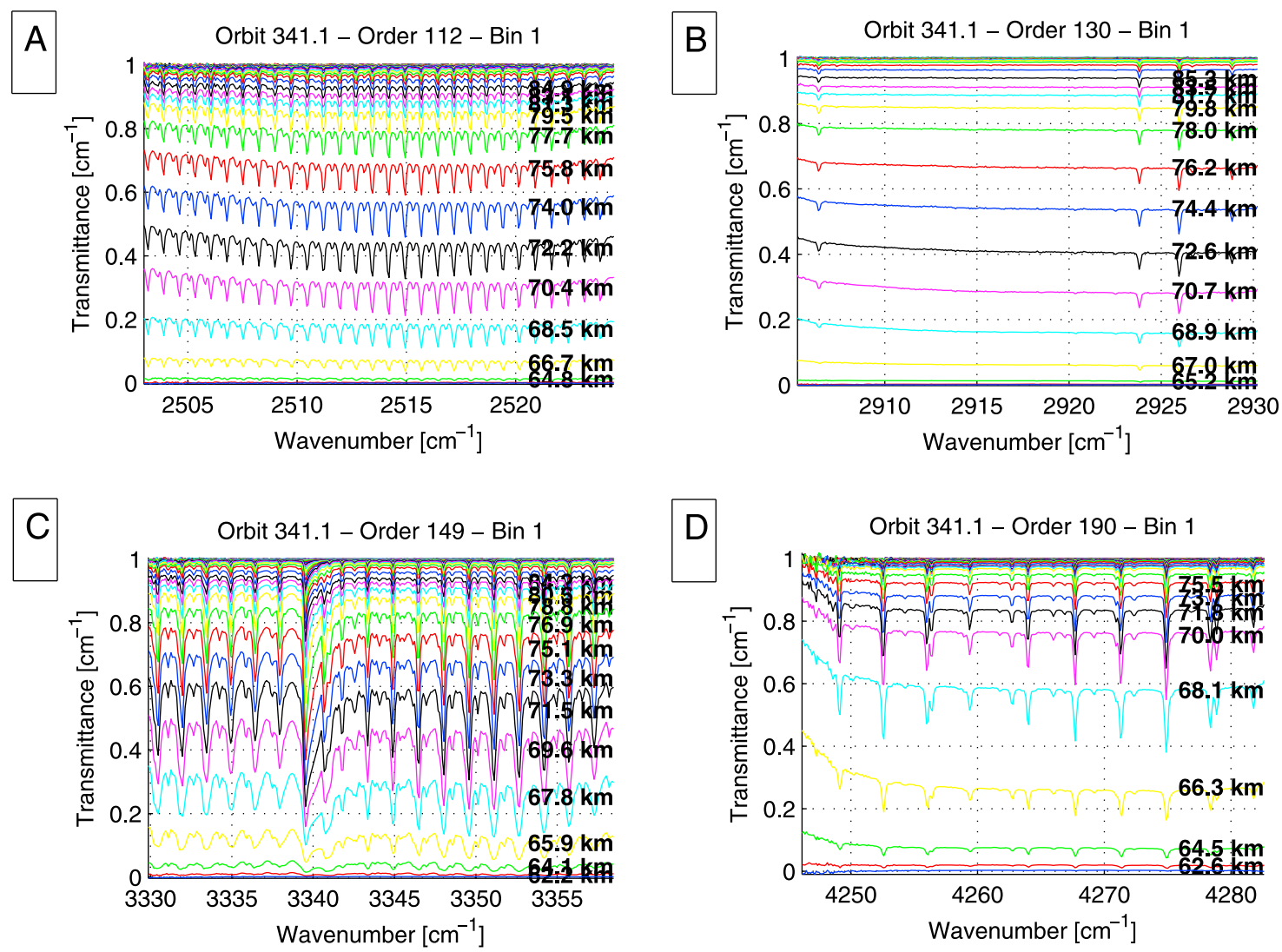

Figure 7. Spectra measured during orbit 341.1 (28 March 2007). The selected orders were (a) 112 , (b) 130 , (c) 149, and (d) 190. Each image depicts all the spectra taken during the occultation in the selected diffraction order. The absorption features observed in Figure 7 a come from ${ }^{16} \mathrm{O}^{12} \mathrm{C}^{18} \mathrm{O}$, in Figure $7 \mathrm{~b}$ from ${ }^{1} \mathrm{H}^{15} \mathrm{Cl}$ and ${ }^{1} \mathrm{H}^{15} \mathrm{Cl}$, in Figure $7 \mathrm{c}$ from ${ }^{16} \mathrm{O}^{12} \mathrm{C}^{16} \mathrm{O}$, and in Figure $7 \mathrm{~d}$ from ${ }^{12} \mathrm{C}^{16} \mathrm{O}$.

meaning they have the same value for all $m_{\text {layer }}$ spectra. For this reason, they are independent of the wave number shifts of each layer $d_{i}$.

\subsection{Measurement Error and Pointing Error}

[53] Two external independent sources of errors, coming from different sources are considered in the present work: the measurement error and the satellite pointing error. The first one, the measurement error calculation, has been described by Mahieux et al. [2008]. The signal-to-noise ratio obtained is very good, reaching average values of around 500 up to 3000 .

[54] The second one, the satellite pointing error, is obtained directly from ESOC (ftp://ssols01.esac.esa.int/pub/ data/GDP/VEX/ATTDEV/), the European Space Operation and Control of the European Space Agency, which provides the pointing angle error, from which the altitude error is computed. The largest error values at the limb are of the order of $500 \mathrm{~m}$ for orbits when the satellite is far away of the planet, and less than $50 \mathrm{~m}$ while the satellite is close to the planet.

\section{Examples of Applications}

[55] In the following we will illustrate the method developed above with two different retrieval cases. The focus is placed on the analysis of the method and its merits.
Further scientific discussion on the results, considering a more complete data set, will be pursued in the second part of this series.

\subsection{Carbon Dioxide Retrieval}

[56] One order per occultation has been systematically dedicated to carbon dioxide measurements. The diffraction order $149\left(3329.8-3358.3 \mathrm{~cm}^{-1}\right)$ corresponds to a spectral interval in which the main isotopologue ${ }^{16} \mathrm{O}^{12} \mathrm{C}^{16} \mathrm{O}$ presents a relatively strong absorption band. As mentioned by Vandaele et al. [2008], this band allows us to cover tangent altitudes from about $75 \mathrm{~km}$ up to $120 \mathrm{~km}$. But saturation of the lines generally restricts the minimum altitude to approximately $100 \mathrm{~km}$. To simulate this order, the adjacent orders +1 and -1 are taken into account, ranging from $3307.47 \mathrm{~cm}^{-1}$ to $3380.86 \mathrm{~cm}^{-1}$. The resolution of the instrument in this region is $0.16 \mathrm{~cm}^{-1}$. The three most important bands in intensity, which are included in the simulation, are the 21102 00001, 22202-01101 and 30003-01101 transitions, having maximal intensities of $9.1 \times 10^{-22} \mathrm{~cm}^{-1} /\left(\right.$ molecule $\left.\mathrm{cm}^{-2}\right), 4.4 \times$ $10^{-24} \mathrm{~cm}^{-1} /\left(\right.$ molecule $\left.\mathrm{cm}^{-2}\right)$ and $1.3 \times 10^{-24} \mathrm{~cm}^{-1} /\left(\right.$ molecule $\left.\mathrm{cm}^{-2}\right)$, respectively, comprising 306 lines in total. Figure 7 shows the coverage of this order measurement.

[57] A complete description of the retrieval of orbit 341 $(28 / 03 / 2007)$ is given in the following. Table 2 summarizes the orbit information, while Figure 8 depicts all the spectra measured in the four scanned diffraction orders. 


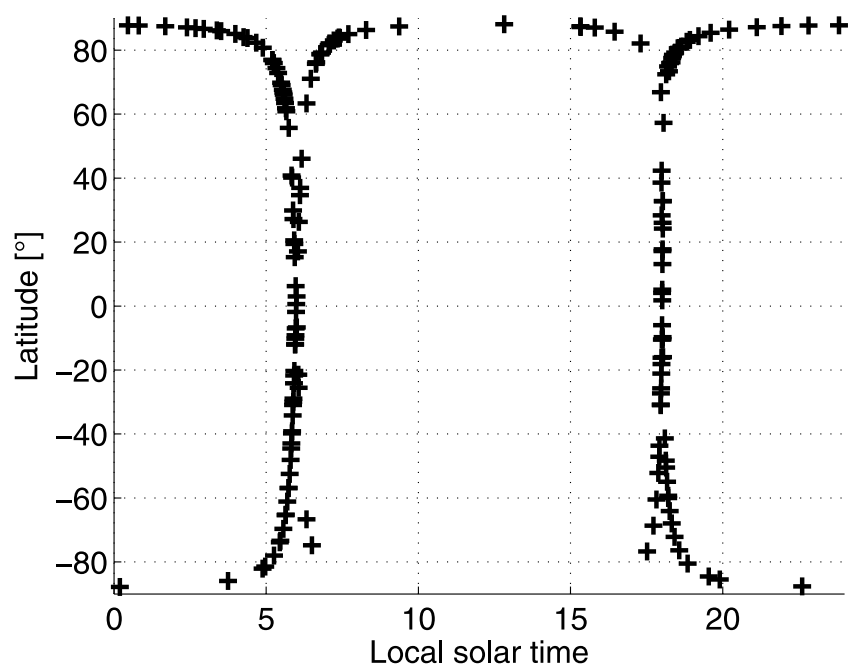

Figure 8. Trace of the measurement points of diffraction order 149 on a local solar time versus latitude map. The measurements occur either at $0600 \mathrm{LT}$ or $1800 \mathrm{LT}$, on the morning or the evening terminators. A gap is seen at the morning terminator between $50^{\circ}$ and $60^{\circ}$ north, as well as on the evening terminator between $35^{\circ}$ and $70^{\circ}$ north. This is due to the orbit geometry, implying that few solar occultations occur for VEX at these latitudes.

The measurements were taken between 0620:01 LT and 0629:54 LT, during an egress case of the satellite. The latitude at the tangent altitude of $65 \mathrm{~km}$ was $82.05^{\circ}$, and the longitude was $348.20^{\circ}$. The local solar time was 17.30 . The speed of the satellite projected on the line of sight was
$-8.76 \mathrm{~km} / \mathrm{s}$. The useful altitude range for the retrieval extended from $102.7 \mathrm{~km}$ up to $120.0 \mathrm{~km}$, resulting from the criteria developed before. The vertical profiles for the $\mathrm{CO}_{2}$ density and the temperature are given in Figure 9. Figure 10 illustrates the quality of the fit, which is performed on only a portion of the recorded spectra (green curve). The layers below $102.7 \mathrm{~km}$ have been removed because some of the lines were saturated, and were not fulfilling the criteria described in section 4.3. The averaging kernels for the main fitted parameters are presented in Figure 11. As expected, the averaging kernels corresponding to the background parameters (a, b, and c, not shown for the latter) are only defined at the level to which they correspond.

[58] The averaging kernels or the $\mathrm{CO}_{2}$ concentrations have maximum values increasing while going deeper in the atmosphere, because there is more spectroscopic information present in the spectra: the path length is longer and the density is higher for low-altitude measurements. It may also be observed that the highest-altitude kernels are also defined at the surrounding altitudes, corresponding to the fact that they influence as well the layers located below them. The averaging kernel for the wave number shift is much more intricate, as a shift in a layer will partially influence all the other layers. No direct conclusion can be drawn in this case.

[59] The error covariances matrices have been calculated for the baseline parameters $a, b$ and $c$, the $\mathrm{CO}_{2}$ density, the temperature and the AOTF fitted values. The error covariances of $a, b, c$ and wave number shift parameters are diagonal matrices, as the parameter of a given layer does not depend on the other layers parameters. The influence of the other layers on the density parameters is observed in its error covariance matrix by showing nonzero values
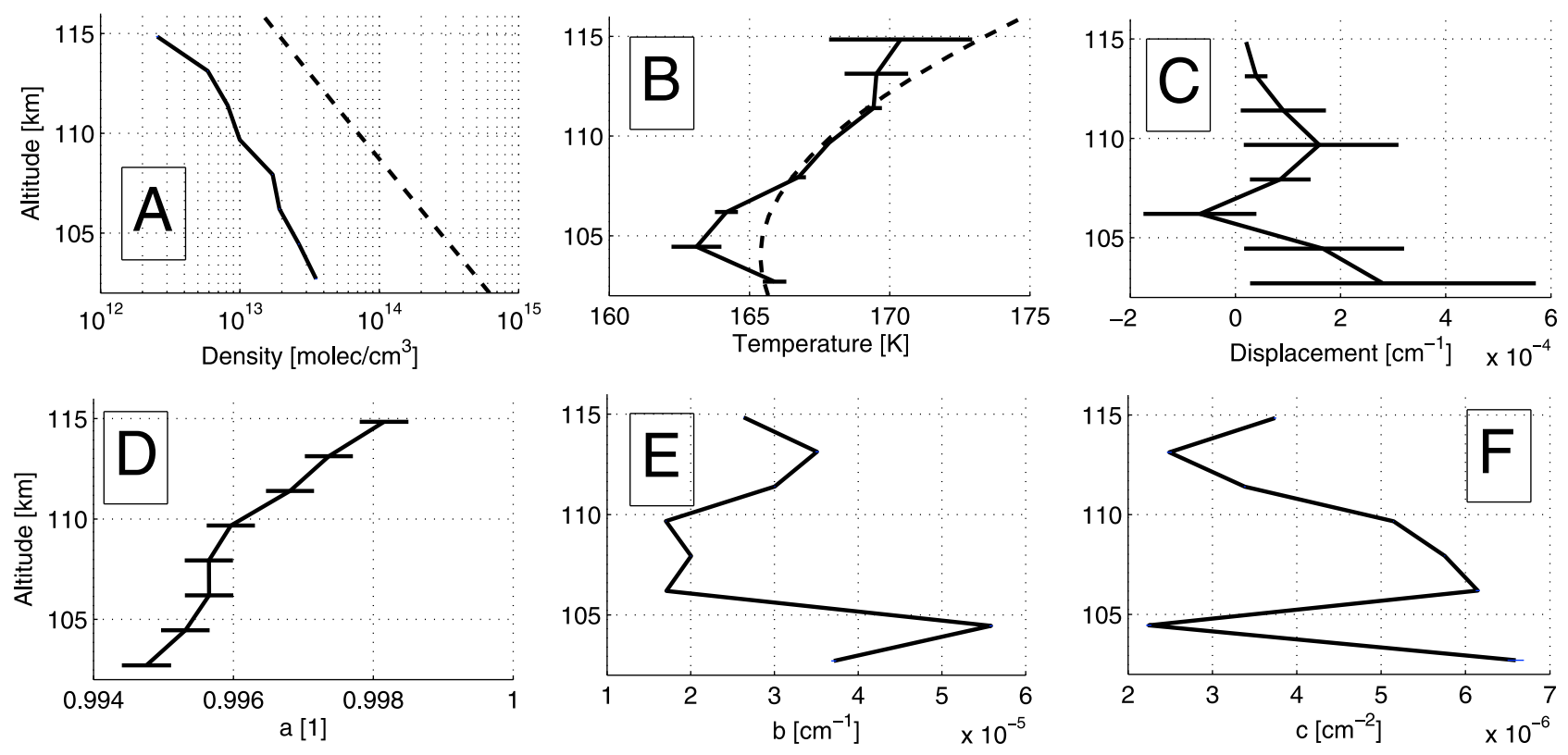

Figure 9. Vertical profiles obtained from the retrieval of the orbit 341, using order 149: (a) $\mathrm{CO}_{2}$ density, (b) temperature, (c) wave number shift, and (d-f) aerosols parameters. Reference vertical profiles (dashed), from the combination of the VIRA model [Seiff et al., 1985] and the VTS3 model [Hedin et al., 1983]; retrieved profile (plain). The errors obtained from the optimal estimation algorithm are also plotted on the graphs. 

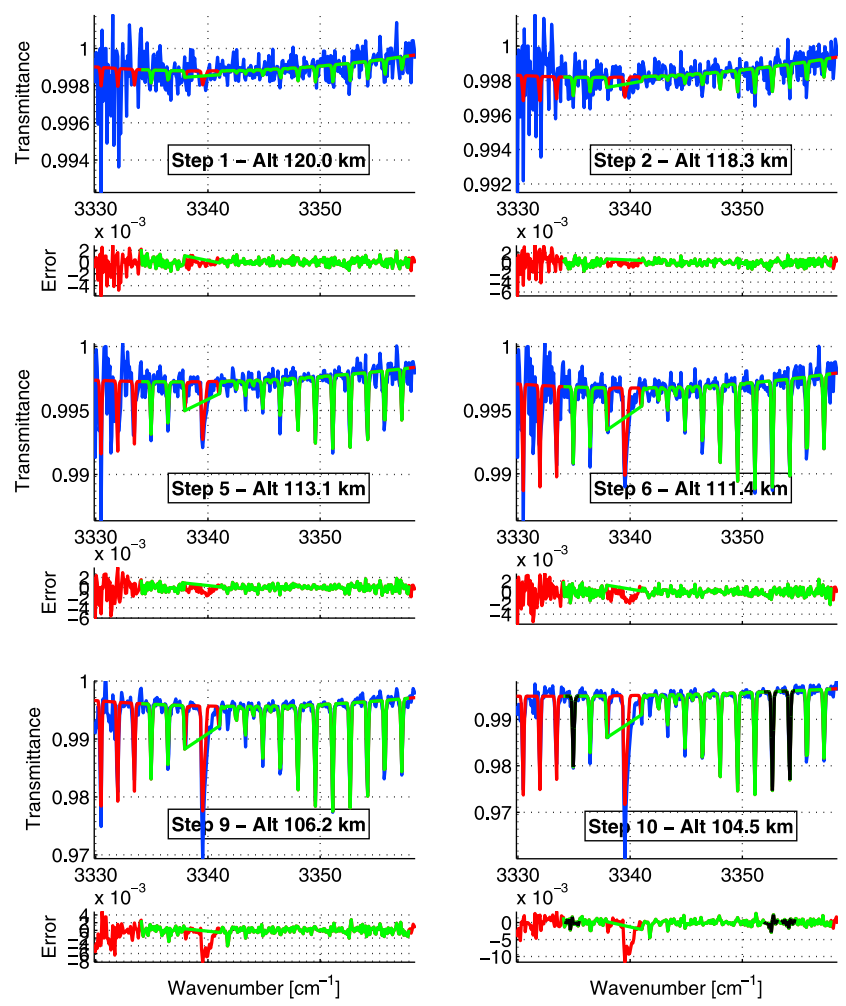
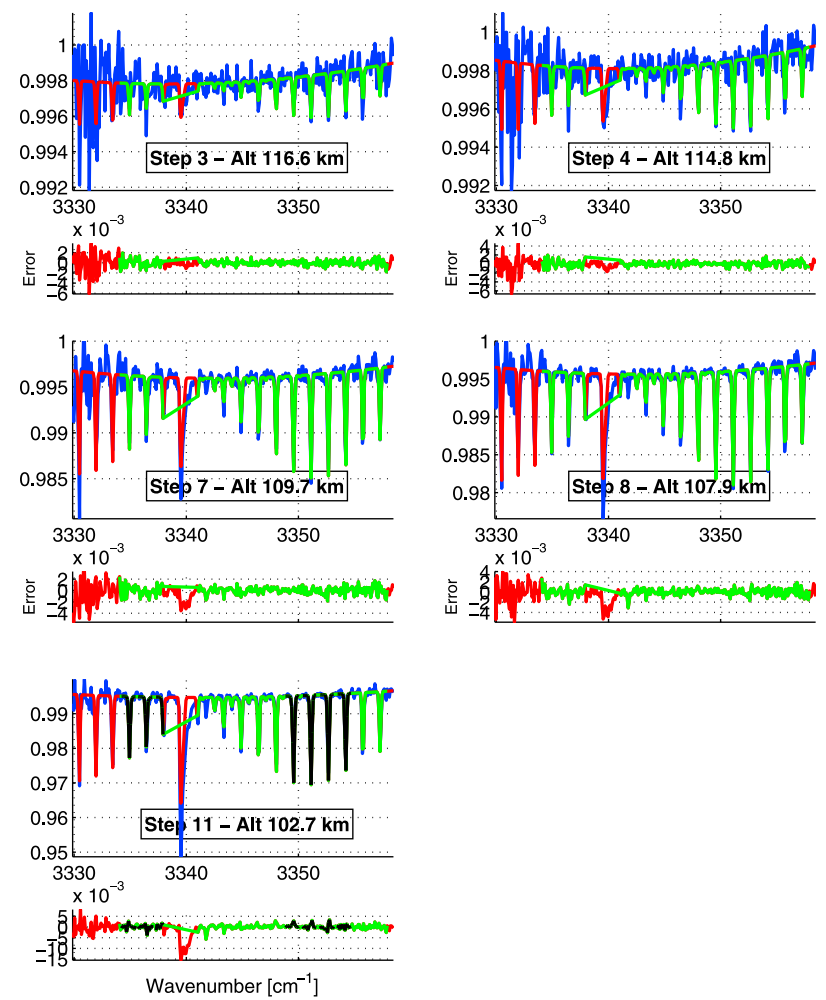

Figure 10. Illustration of the quality of the spectral fit obtained during the $\mathrm{CO}_{2}$ retrieval of orbit 341 , order 149. For each altitude, (top) comparison of the observed (blue) and fitted (green) transmittances (red represents the calculated transmittance outside the fitting wave number range), and (bottom) illustration of the residuals (observed-fitted transmittances).
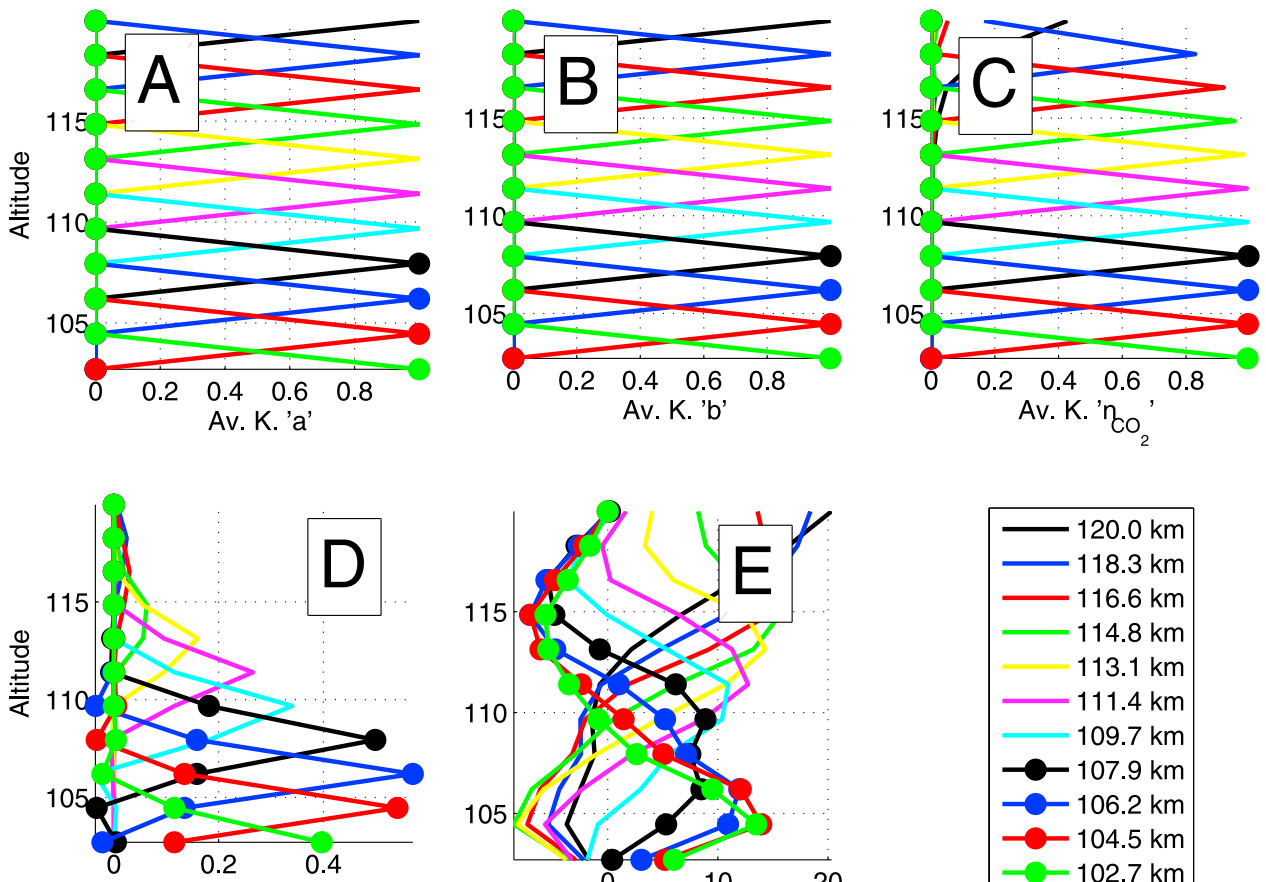

Av. K. 'temperature'
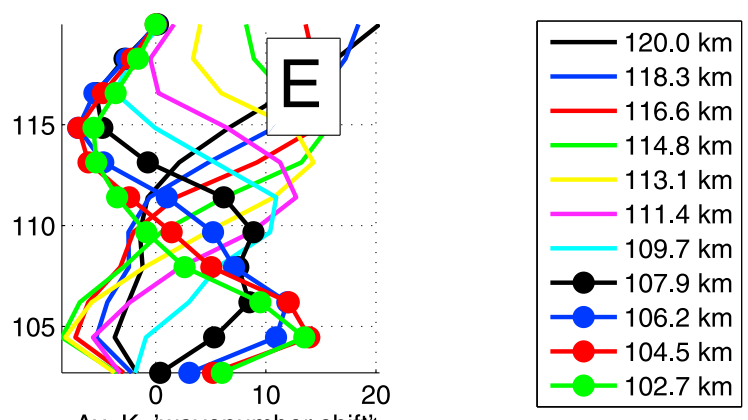

Av. K. 'wavenumber spift'

Figure 11. Averaging kernels of the last step of the optimal estimation algorithm from the retrieval of $\mathrm{CO}_{2}$ of orbit 341, order 149: (a) aerosols a parameter, (b) aerosols b parameter, (c) $\mathrm{CO}_{2}$ vertical densities, (d) rotational temperature vertical profile, and (e) wave number shift. The averaging kernels show the area of dependency of each variable. 
Table 2. Details of the Orbit 341.1 on 28 March $2007^{\mathrm{a}}$

\begin{tabular}{|c|c|c|c|c|c|c|}
\hline UTC Time & $\begin{array}{l}\text { Tangent Altitude } \\
(\mathrm{km})\end{array}$ & $\begin{array}{l}\text { Latitude } \\
\text { (deg) }\end{array}$ & $\begin{array}{l}\text { Longitude } \\
\text { (deg) }\end{array}$ & $\begin{array}{l}\text { Pointing Angle } \\
\text { (deg) }\end{array}$ & $\begin{array}{c}\text { Distance to } \\
\text { Surface }(\mathrm{km})\end{array}$ & $\begin{array}{c}\text { Height of the } \\
\text { Projected Slit }(\mathrm{km})\end{array}$ \\
\hline 2007-03-28T06:25:45.880 & 120.0 & 82.7 & 349.2 & 117.9 & 934.0 & 2.0 \\
\hline 2007-03-28T06:25:44.880 & 118.3 & 82.7 & 349.2 & 118.0 & 936.6 & 2.0 \\
\hline 2007-03-28T06:25:43.880 & 116.6 & 82.7 & 349.2 & 118.1 & 939.2 & 2.0 \\
\hline 2007-03-28T06:25:42.880 & 114.8 & 82.7 & 349.1 & 118.1 & 941.8 & 2.0 \\
\hline 2007-03-28T06:25:41.880 & 113.1 & 82.6 & 349.1 & 118.2 & 944.4 & 2.0 \\
\hline 2007-03-28T06:25:40.880 & 111.4 & 82.6 & 349.0 & 118.3 & 947.0 & 2.0 \\
\hline 2007-03-28Т06:25:39.880 & 109.7 & 82.6 & 349.0 & 118.4 & 949.6 & 2.0 \\
\hline 2007-03-28T06:25:38.880 & 107.9 & 82.6 & 349.0 & 118.4 & 952.2 & 2.0 \\
\hline 2007-03-28T06:25:37.880 & 106.2 & 82.6 & 348.9 & 118.5 & 954.8 & 2.1 \\
\hline 2007-03-28T06:25:36.880 & 104.5 & 82.5 & 348.9 & 118.6 & 957.5 & 2.1 \\
\hline 2007-03-28T06:25:35.880 & 102.7 & 82.5 & 348.9 & 118.6 & 960.1 & 2.1 \\
\hline
\end{tabular}

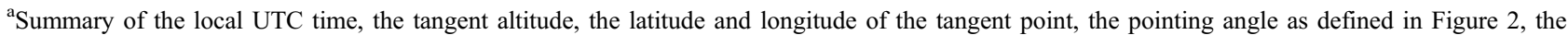
distance between the surface of Venus and Venus Express and the height of the projected slit at the tangent point.

outside the diagonal: the upper layers have an influence on the lower layers, coming from the onion peeling method. It is not observed for the error covariances of the temperature, as the temperature dependence is weak.

[60] The vertical profiles described here above cover an altitude range between 120 and $102.7 \mathrm{~km}$. As explained before, the retrieval can take place in a given order when the absorption features appear in the spectra, and is stopped when saturation of the absorption lines occurs. Using other diffraction orders, other $\mathrm{CO}_{2}$ bands with different line intensities can be investigated, allowing a wider vertical coverage. This is illustrated in Figures 12 and 13 where the densities of $\mathrm{CO}_{2}$ and the rotational temperature obtained using different orders in quasi consecutive orbits are presented.

\subsection{Carbon Monoxide Retrieval}

[61] The main isotopologue ${ }^{12} \mathrm{C}^{16} \mathrm{O}$ of carbon monoxide presents some absorption features in diffraction order 190 (4246.1-4282.4 $\mathrm{cm}^{-1}$ ). Two transitions are considered: the (2-0) band, with 28 lines and a maximum intensity of $4.5 \times 10^{-21} \mathrm{~cm}^{-1} /\left(\right.$ molecule $\left.\mathrm{cm}^{-2}\right)$ and the (3-1) band with 21 lines and a maximum intensity of $3.2 \times 10^{-28} \mathrm{~cm}^{-1} /$ (molecule $\mathrm{cm}^{-2}$ ). To simulate this order, the adjacent orders +1 and -1 are taken into account, ranging from $4223.7 \mathrm{~cm}^{-1}$ to $4305.0 \mathrm{~cm}^{-1}$. The resolution of the instrument in this region is $0.23 \mathrm{~cm}^{-1}$.

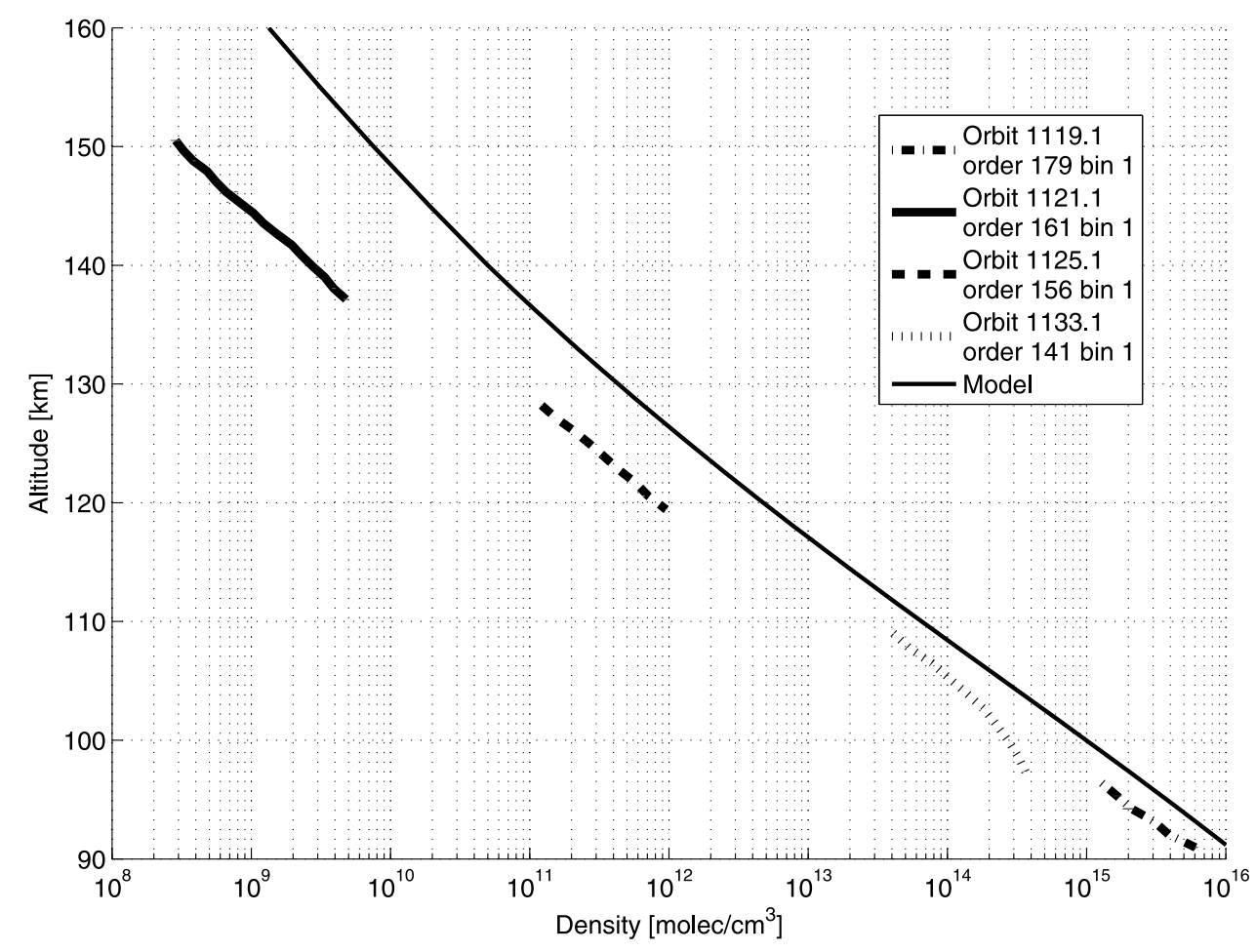

Figure 12. $\mathrm{CO}_{2}$ vertical profiles coming from four different diffraction orders, allowing covering a wider vertical altitude range. They were obtained from the orbits 1119.1 (14 May 2009, 80.4 ${ }^{\circ} \mathrm{N}$, 1830 LT), 1221.1 (16 May 2009, 83. $\left.{ }^{\circ} \mathrm{N}, 1648 \mathrm{LT}\right), 1125.1$ (20 May 2009, 84.6 $\left.{ }^{\circ} \mathrm{N}, 1912 \mathrm{LT}\right)$, and 1133.1 (28 May 2009, 87.6 ${ }^{\circ}$, 2200 LT). 


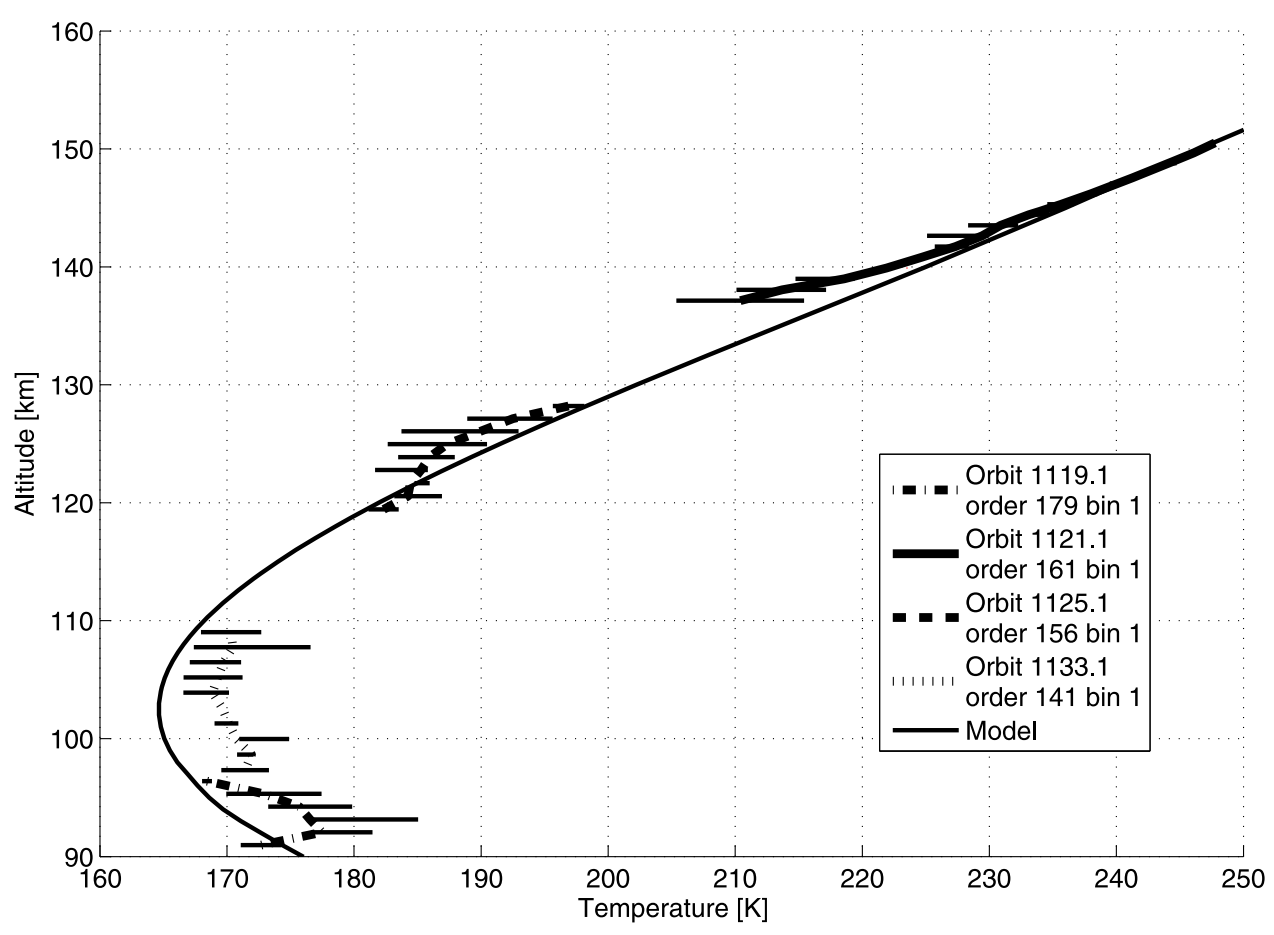

Figure 13. $\mathrm{CO}_{2}$ rotational temperature vertical profiles coming from four different diffraction orders, allowing covering a wider vertical altitude range. They were obtained from the orbits 1119.1 (14 May $\left.2009,80.4^{\circ} \mathrm{N}, 1830 \mathrm{LT}\right), 1221.1$ (16 May $\left.2009,83.1^{\circ} \mathrm{N}, 1648 \mathrm{LT}\right), 1125.1$ (20 May 2009, $84.6^{\circ} \mathrm{N}, 1912 \mathrm{LT}$ ), and 1133.1 (28 May $2009,87.6^{\circ} \mathrm{N}, 2200 \mathrm{LT}$ ).
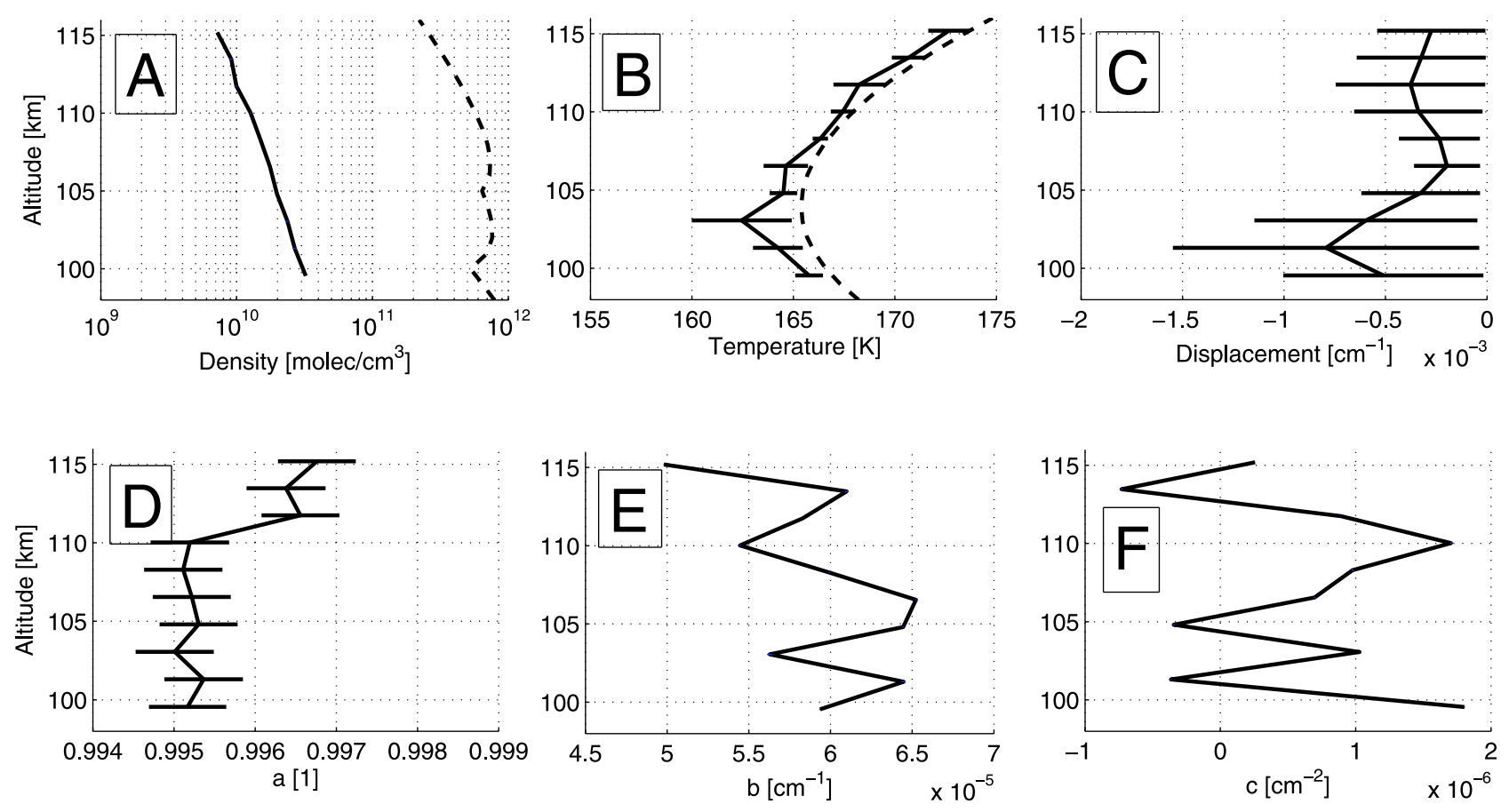

Figure 14. Vertical profiles of (a) CO density, (b) temperature, (c) wave number shift, and (d-f) aerosols parameters obtained from the retrieval of the orbit 341, using order 190: retrieved profile (plain); reference vertical profiles (dashed), combination of the VIRA model [Seiff et al., 1985] and the VTS33 model [Hedin et al., 1983]. The temperature is the one retrieved during the $\mathrm{CO}_{2}$ retrieval. The errors obtained from the optimal estimation algorithm are also plotted on the graphs. 

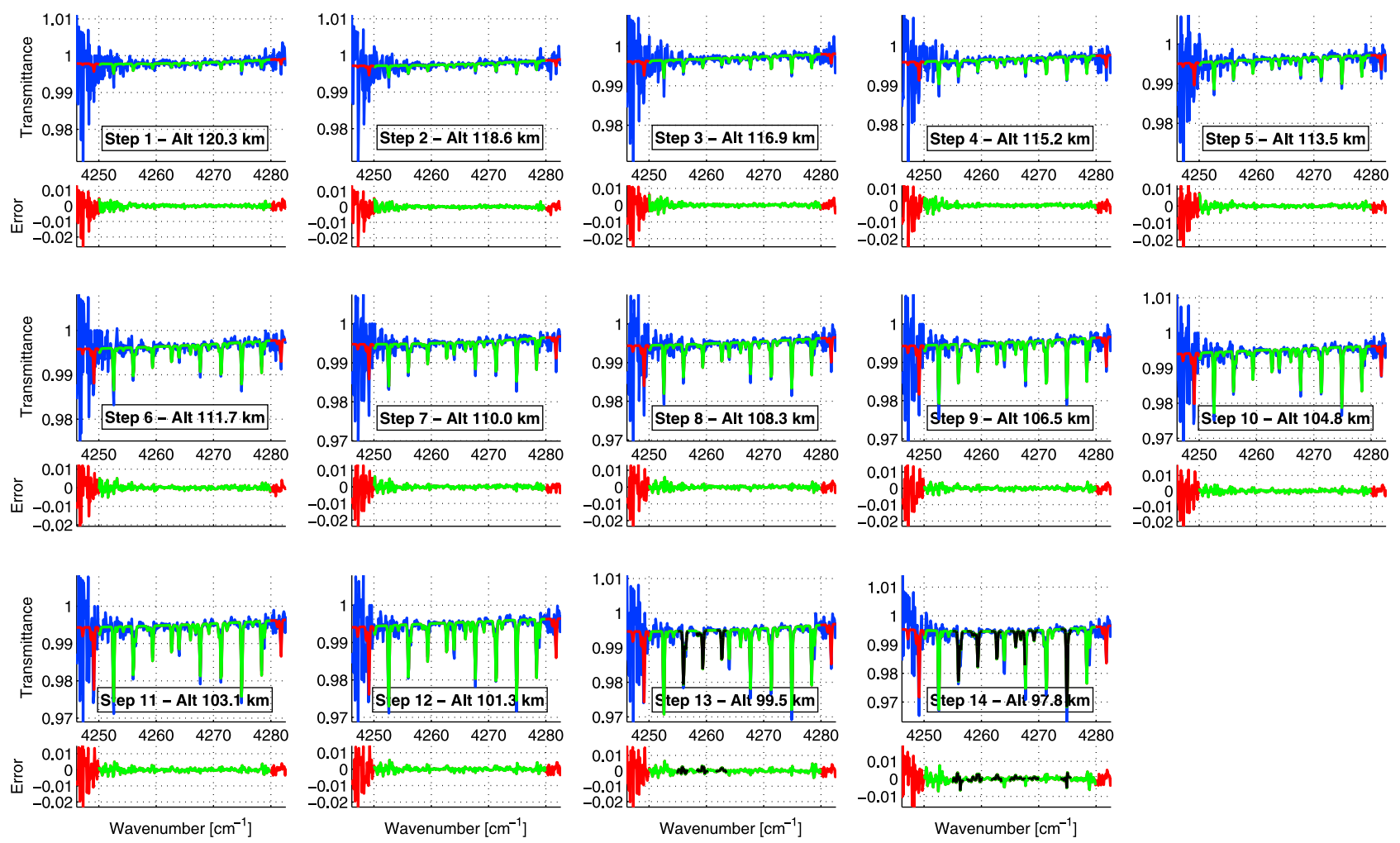

Figure 15. Illustration of the quality of the spectral fit obtained during the $\mathrm{CO}$ retrieval of orbit 341 , order 190. For each altitude, (top) comparison of the observed (blue) and fitted (green) transmittances (red represents the calculated transmittance outside the fitting wave number range), and (bottom) illustration of the residuals (observed-fitted transmittances).
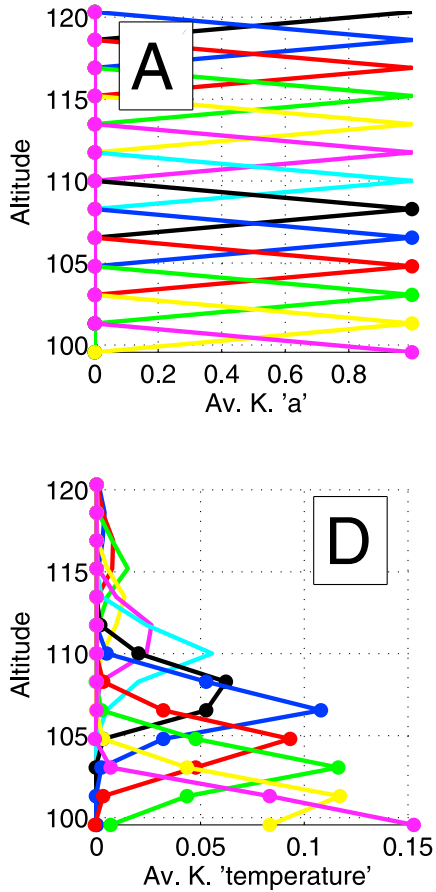
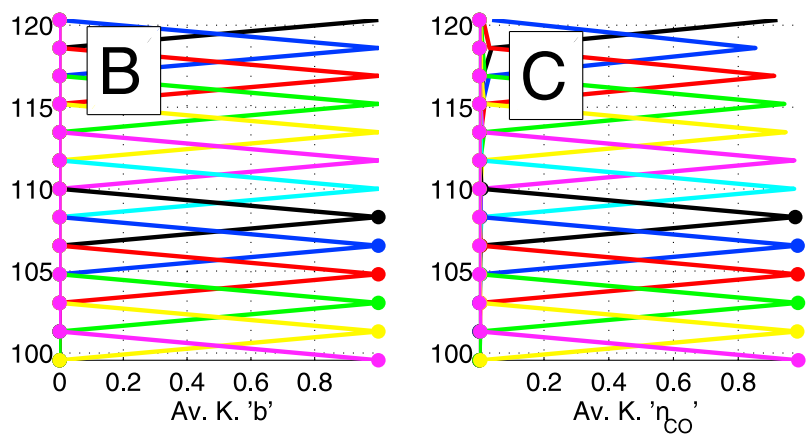

Figure 16. Averaging kernels of the last step of the optimal estimation algorithm from the retrieval of CO of orbit 341, order 190: (a) aerosols a parameter, (b) aerosols b parameter, (c) CO vertical densities, and (d) rotational temperature profile. The averaging kernels show the area of dependency of each variable. 
[62] Order 190 was scanned during occultation 341, the same one used to illustrate the retrieval of $\mathrm{CO}_{2}$. The preliminary altitude range was defined from $119 \mathrm{~km}$ down to $65 \mathrm{~km}$, but during the fit it has been reduced to $119 \mathrm{~km}$ down to $99.7 \mathrm{~km}$, because of the saturation occurring at the lower altitudes. Similar to what has been shown for the $\mathrm{CO}_{2}$ results; Figures 14-16 show the results of the fitting procedure in the case of $\mathrm{CO}$. As for $\mathrm{CO} 2$ the concentrations in one layer is almost independent of the surrounding layers, and the information content also increase when going deeper in the atmosphere. In this example, temperature has also been retrieved and is favorably compared to the temperature retrieved from $\mathrm{CO} 2$ (see Figures $9 \mathrm{~b}$ and 14b).

\section{Conclusion}

[63] The present paper shows how the densities of some key constituents of the atmosphere of Venus, as well as rotational temperature profiles can be retrieved from the SOIR data, using a retrieval technique based on the $\mathrm{OE}$ method. This method allows the simultaneous derivation of the densities of all the target species, including different isotopologues. The total pressure and total density profiles can also be obtained using a specific procedure, in the case of carbon dioxide retrievals.

[64] The error bars on the retrieved density are lower than $6 \%$, and on the temperature are lower than $1.5 \%$. The method provides reliable vertical profiles that will be used to construct a database of the upper Venus atmosphere at the terminator, and will allow us to study the temporal and latitudinal variations of the composition of the atmosphere. A $\mathrm{CO}_{2}$ climatology is being built and will be described and discussed in the forthcoming companion paper. At the same time, a detailed inventory of the composition of the atmosphere is being done in terms of $\mathrm{CO}, \mathrm{H}_{2} \mathrm{O} / \mathrm{HDO}, \mathrm{HF}, \mathrm{HCl}$, or $\mathrm{SO}_{2}$.

[65] Acknowledgments. Venus Express is a planetary mission from the European Space Agency (ESA). We wish to thank all ESA members who participated in the mission, in particular, H. Svedhem and O. Witasse. We thank our collaborators at IASB-BIRA (Belgium), Latmos (France), and IKI (Russia). We thank CNES, CNRS, Roskosmos, and the Russian Academy of Science. The research program was supported by the Belgian Federal Science Policy Office and the European Space Agency (ESA, PRODEX program, contracts C 90268, 90113, and 17645).

\section{References}

Altieri, F., L. Zasova, E. D’Aversa, G. Bellucci, F. G. Carrozzo, B. Gondet, and J.-P. Bibring (2009), $\mathrm{O}_{2} 1.27 \mu \mathrm{m}$ emission maps as derived from OMEGA/ MEx data, Icarus, 204(2), 499-511, doi:10.1016/j.icarus.2009.07.022.

Belyaev, D., O. Korablev, A. Fedorova, J.-L. Bertaux, A.-C. Vandaele, F. Montmessin, A. Mahieux, V. Wilquet, and R. Drummond (2008), First observations of $\mathrm{SO}_{2}$ above Venus' clouds by means of solar occultation in the infrared, J. Geophys. Res., 113, E00B25, doi:10.1029/ 2008JE003143, [printed 114(E5), 2009].

Bertaux, J. L., D. Nevejans, O. Korablev, E. Villard, E. Quémerais, E. Neefs, F. Montmessin, F. Leblanc, J. P. Dubois, and E. Dimarellis (2007), SPICAV on Venus Express: Three spectrometers to study the global structure and composition of the Venus atmosphere, Planet. Space Sci., 55(12), 1673-1700, doi:10.1016/j.pss.2007.01.016.

Bingen, C., F. Vanhellemont, and D. Fussen (2003), A new regularized inversion method for the retrieval of stratospheric aerosol size distributions apllied to 16 years of SAGE II data (1984-2000): Method, results and validation, Ann. Geophys., 21, 797-804, doi:10.5194/angeo21-797-2003.

Clancy, R. T., B. Sandor, and G. H. Moriarty-Schieven (2003), Observational definition of the Venus mesopause: Vertical structure, diurnal variation, and temporal instability, Icarus, 161(1), 1-16, doi:10.1016 S0019-1035(02)00022-2.

Clancy, R. T., B. J. Sandor, and G. H. Moriarty-Schieven (2008), Venus upper atmospheric $\mathrm{CO}$, temperature, and winds across the afternoon/ evening terminator from June 2007 JCMT sub-millimeter line observations, Planet. Space Sci., 56(10), 1344-1354, doi:10.1016/j.pss.2008.05.007

de Bergh, C., V. I. Moroz, F. W. Taylor, D. Crisp, B. Bézard, and L. V. Zasova (2006), The composition of the atmosphere of Venus below $100 \mathrm{~km}$ altitude: An overview, Planet. Space Sci., 54(13-14), 1389-1397, doi:10.1016/j.pss.2006.04.020.

Esposito, L. W. (1983), The clouds and hazes on Venus, in Venus, edited by D.M. Hunten et al., pp. 484-564, Univ. of Ariz. Press, Tucson.

Fedorova, A., et al. (2008), $\mathrm{HDO}$ and $\mathrm{H}_{2} \mathrm{O}$ vertical distribution and isotopic ratio in the Venus mesosphere by SOIR spectrometer on board Venus Express, J. Geophys. Res., 113, E00B22, doi:10.1029/2008JE003146, [printed 114(E5), 2009].

Gallery, W. O., F. X. Kneizys, and S. A. Clough (1983), Air Mass Computer Program for Atmospheric Transmittance/Radiance Calculation: FSCATM, Air Force Geophys. Lab., Hanscom AFB, Mass.

Gilli, G., M. A. Lopez-Valverde, P. Drossart, G. Piccioni, S. Erard, and A. Cardesin-Moinelo (2009), Limb observations of $\mathrm{CO}_{2}$ and $\mathrm{CO}$ nonLTE emissions in the Venus atmosphere by VIRTIS/Venus Express, J. Geophys. Res., 114, E00B29, doi:10.1029/2008JE003112.

Hedin, A. E., H. B. Niemann, and W. T. Kasprzak (1983), Global empirical model of the Venus thermosphere, J. Geophys. Res., 88(A1), 73-83, doi:10.1029/JA088iA01p00073.

Lane, W. A., and R. Opstbaum (1983), High altitude Venus haze from Pioneer Venus limb scans, Icarus, 54(1), 48-58, doi:10.1016/0019-1035(83) 90071-4.

Mahieux, A., et al. (2008), In-flight performance and calibration of SPICAV SOIR on board Venus Express, Appl. Opt., 47(13), $2252-$ 2265, doi:10.1364/AO.47.002252.

Mahieux, A., V. Wilquet, R. Drummond, D. Belyaev, A. Fedorova, and A. C. Vandaele (2009), A new method for determining the transfer function of an Acousto optical tunable filter, Opt. Express, 17, 2005-2014, doi:10.1364/OE.17.002005

Mueller-Wodarg, I., and S. Tingle (2008), Vertical structure above the clouds: Towards a unified model, paper presented at XLIII Rencontres de Moriond, Venus Express Scientific Workshop, Eur. Space Agency, La Thuile, Italy, 3-7 Mar.

NASA Ancillary Information Facility (NAIF) (2009), The SPICE Toolkit, NASA, Pasadena, Calif.

Nevejans, D., et al. (2006), Compact high-resolution space-borne echelle grating spectrometer with AOTF based on order sorting for the infrared domain from 2.2 to 4.3 micrometer, Appl. Opt., 45(21), 5191-5206, doi:10.1364/AO.45.005191.

Rodgers, C. D. (1990), Characterization and error analysis of profiles retrieved from remote sounding measurements, J. Geophys. Res., 95(D5), 5587-5595, doi:10.1029/JD095iD05p05587.

Rodgers, C. D. (2000), Inverse Methods for Atmospheric Sounding: Theory and Practice, Univ. of Oxford, Oxford, U. K.

Rothman, L. S., et al. (2009), The HITRAN 2008 molecular spectroscopic database, J. Quant. Spectrosc. Radiat. Transfer, 110(9-10), 533-572, doi:10.1016/j.jqsrt.2009.02.013.

Russel, J. M., and S. R. Drayson (1972), The inference of atmospheric ozone using satellite horizon measurements in the $1042 \mathrm{~cm}-1$ band, J. Atmos. Sci., 29, 376.

Sandor, B. J., and R. T. Clancy (2005), Water vapor variations in the Venus mesosphere from microwave spectra, Icarus, 177, 129-143, doi:10.1016/ j.icarus.2005.03.020.

Schroeder, D. J., and R. L. Hilliard (1980), Echelle efficiencies: Theory and experiment, Appl. Opt., 19(16), 2833-2841, doi:10.1364/AO.19.002833.

Seiff, A., J. T. Schofield, A. Kliore, F. W. Taylor, S. S. Limaye, H. E. Revercomb, L. A. Sromovsky, V. V. Kerzhanovich, V. I. Moroz, and M. Y. Marov (1985), Models of the structure of the atmosphere of Venus from the surface to 100 kilometers altitude, Adv. Space Res., 5(11), 3-58, doi:10.1016/0273-1177(85)90197-8.

Svedhem, H., et al. (2007), Venus Express: The first European mission to Venus, Planet. Space Sci., 55(12), 1636-1652, doi:10.1016/j.pss.2007.01.013.

Titov, D. V., et al. (2006), Venus Express science planning, Planet. Space Sci., 54 (13-14), 1279-1297, doi:10.1016/j.pss.2006.04.017.

Vandaele, A. C., M. Kruglanski, and M. De Mazière (2006), Simulation and retrieval of atmospheric spectra using ASIMUT, paper presented at Atmospheric Science Conference, Eur. Space Agency, Frascati, Italy.

Vandaele, A. C., et al. (2008), Composition of the Venus mesosphere measured by SOIR on board Venus Express, J. Geophys. Res., 113, E00B23, doi:10.1029/2008JE003140, [printed 114(E5), 2009].

Wilquet, V., A. Fedorova, F. Montmessin, R. Drummond, A. Mahieux, A. C. Vandaele, E. Villard, O. Korablev, and J.-L. Bertaux (2009), Pre- 
liminary characterization of the upper haze by SPICAV/SOIR solar occultation in UV to mid-IR onboard Venus Express, J. Geophys. Res., 114, E00B42, doi:10.1029/2008JE003186.

J. L. Bertaux, LATMOS, 11 Bd d'Alembert, F-78280 Guyancourt, France.
R. Drummond, A. Mahieux, E. Neefs, S. Robert, A. C. Vandaele, and V. Wilquet, Planetary Aeronomy, Belgian Institute for Space Aeronomy, 3 ave. Circulaire, B-1180 Brussels, Belgium. (arnaud.mahieux@ aeronomie.be)

A. Federova, Space Research Institute, 84/32 Profsoyuznaya Str. 117997, Moscow, Russia. 